\title{
Peer Effects, Cooperation and Competition in Human Capital Formation
}

\author{
Román Andrés Zárate* \\ Advisor: Daniel Mejía ${ }^{\dagger}$
}

January 26, 2012

\begin{abstract}
Economic literature has identified positive effects of peer abilities on individual achievement. However, the intuitive arguments supporting this evidence are not clear. This article presents a specific mechanism: cooperation and competition among group members; more precisely, the presence of positive and negative externalities in human capital accumulation. First, I develop an economic model that incorporates both kinds of externalities and shows the existence of an optimal level of competition between group members that maximizes human capital accumulation. Then, using data from PISA (2000) and an empirical strategy that controls for potential endogeneity issues, I find empirical evidence supporting the main results of the theoretical model. Namely, I find robust evidence of a non-linear effect of competition on academic performance. These results are consistent with the proposed model and the presence of positive technological externalities in educational production functions.
\end{abstract}

JEL Classification Codes: D62, I21, J24

Keywords: Peer effects, Cooperation, Competition, PISA.

\footnotetext{
${ }^{*}$ Contact information: ra.zarate22@uniandes.edu.co. I'm grateful to Daniel Mejía for being my advisor in this paper. I also want to thank Andrés Álvarez and Pablo Querubín for their valuable comments and suggestions. Finally, to Valentina Díaz and Santiago Melo for reading previous versions of this paper.

${ }^{\dagger}$ Contact information: dmejia@uniandes.edu.co
} 


\section{Introduction}

Peer effects have been widely studied in economic literature. The importance of identifying them correctly has been the main issue of empirical analyses. Most of the economic literature on the topic has focused on finding an unbiased estimation using a source of exogenous variation. Nevertheless there is no strong empirical or theoretical evidence about the channels or mechanisms through which peer effects operate. This article proposes a particular mechanism: cooperation and competition among the members of a group. Both topics, cooperation and competition, have been studied in economic literature in different contexts, but there is not enough evidence on education outcomes and students' decisions. The existing literature on this topic is not clear for different reasons, mainly due to strong assumptions in theoretical analyses and a lack of causal identification in empirical studies. This paper tries to overcome both problems by using weaker assumptions in the theoretical analysis and an empirical strategy that allows for exogenous variation in the levels of competition and cooperation faced by students.

Different authors have pointed out the importance of peer effects based on decisions made by parents, schools and policy makers' about how children should be allocated to different groups. In particular, under the presence of peer effects, the group in which a student is allocated today affects his or her future cognitive and labor outcomes. Then, it would be desirable to promote certain types of educational systems. For example, the correct estimation of peer effects is important when determining if tracking systems, in which students are allocated with peers of similar abilities, are more efficient than others. The main problem in identifying these effects is self-selection; the group in which a student is allocated depends on his parents' preferences and on restrictions imposed by the educational system. Therefore, the positive effect of peers may be caused by selection decisions instead of a real mechanism in which peers affect students' outcomes. Under this problem, most empirical analyses have focused on finding an exogenous source of variation that explains peer composition but not students' decisions or outcomes.

For example, Zimmerman (2003), Sacerdote (2001) and Foster (2006) use random assignment of roommates as a natural experiment for an unbiased estimation 1 . Other authors use different sources of exogenous variation: Hoxby (2000) uses race and gender variation across adjacent cohorts as an instrument of peer characteristics; Lefgren (2004) uses variation in school tracking policies; and Dills (2005) uses the presence of a magnet school that selects high quality students

\footnotetext{
${ }^{1}$ Other research has focused on heterogeneous impacts of peer effects. In particular, Brunello, De Paola \& Scoppa (2009) use the same source of variation (randomized assignment of roommates) for evaluating peer effects in an Italian University. They find positive peer effects for students enrolled in hard science programs and no effect for those enrolled in humanities or social sciences.
} 
from throughout the school district. The study of Hanusheck et al. (2009) uses school and grade fixed effects in order to control for unobserved characteristics that cause self-selection of students. Other authors have used housing mobility programs to identify peer effects (Rosenbaum (2000) and Souza Briggs (1997)). Although these effects have been identified and widely studied in economic literature, there is still a lack of information about the channels through which peer effects take place. Hoxby (2000) provides some information about potential channels that may explain how these effects operate.

[...] it is useful to clear about what peer effects include. Peer effects do include students teaching one another, but direct peer instruction is only the tip of the iceberg. A student's innate ability can affect his peers, not only through knowledge spillovers but through his influence on classroom standards. A student determined behavior may affect his peers. For instance, a student who has not learned self-discipline at home may disrupt the classroom. Peer effects may follow lines like disability, race gender, or family income: a learning disabled child may draw disproportionately on teacher time, racial or gender tension in the classroom may interfere with learning, richer parents may purchase learning resources that get spread over a classroom [...] (Hoxby, 2000)

As it can be seen, some intuitive arguments have been mentioned in the literature. However, most of them have not been empirically analyzed. In order to understand those mechanisms it is important to think in terms of agents, exogenous parameters, and endogenous decisions which can alter cognitive outcomes. For example, Dupas, Duflo \& Kremer (2008) use a randomized experiment of tracking in Kenya for analyzing both, the effects of peers and tracking systems, on educational outcomes. They develop a theoretical model in which they consider the mechanisms through which this variation occurs are not only peer composition, but also teachers' effort decisions and academic level chosen for tests and learning. Using a regression discontinuity design, the authors find no difference in test scores between students allocated to the lower ability section and those allocated to the higher ability group. The authors show that this result is consistent with their theoretical analysis. However, it is plausible to think that there are other mechanisms or explanations to these results. Specifically, students' preferences and effort decisions based on expected ranking in the final test scores distribution ${ }^{2}$.

\footnotetext{
${ }^{2}$ Dupas, Duflo \& Kremer (2008) argue that the result they find is explained by teachers decisions. They assume that students near the median of the initial test are very similar in other characteristics. Given that they do not find differences on final test scores between students allocated to higher and lower sections, but they do find the presence of positive peer effects, they conclude that teachers' decisions about the academic level of their courses is the mechanism that explains this pattern. My perspective is based on students' preferences and decisions. The student with the lowest ability in the high ability group can exert lower or higher levels of effort due to his expected position in the final test scores distribution. If this mechanism can explain this result, then competitive or cooperative attitudes from students are essential in the analysis of how students should be allocated.
} 
This paper focuses on student's decisions and preferences; in particular, preferences for her ranking in test scores distribution and for the total human capital accumulated by herself, as well as her decisions on how much effort to exert and the level of cooperation between them. Specifically, it analyzes how cooperation and competition can alter students' decisions and cognitive outcomes. On the one hand, it is important to wonder for the presence of positive technological externalities in the educational production functions. Under the presence of these externalities, cooperation decisions of student $i$ can positively affect the educational outcomes of student $j$. On the other hand, cooperative environments can diminish group educational outcomes if students perceive individual and group effort levels as substitutes. Under this perception, more cooperative environments produce free-riding effects in which each individual expects other students to help her and, as a consequence, reduces her effort. This would result in a lower overall group effort which would have a negative impact on educational performance.

Even though there is little evidence on cooperative or competitive attitudes of a group and their effect on cognitive outcomes, the topic is related to a vast economic literature. For example, it has been suggested that there are positive externalities in human capital accumulation. Specifically, Lucas (1988) introduced average human capital in the society as an argument in the production function. This element captures the existence of positive technological externalities because it shows how the construction and spreading of ideas constitute social processes in which interactions among individuals are essential. Then, if relations among students also have these positive externalities, cooperative attitudes would increase their accumulated human capital, and this would translate into higher academic test scores.

On the other hand, Lazear \& Rosen (1981) show that individuals would exert higher effort levels if wages are based on relative positions of production levels. This means that tournament systems in which individual rewards depend on their ranking would increase effort levels. In education processes this can be seen as students having a higher concern for their ranking. However, Lazear (1985) shows that this kind of incentives can create higher levels of sabotage between workers of a firm. Given this result, it is possible to think that in educational outcomes, individual concerns for ranking would also have a negative impact on academic performance. This can be explained by the students' incentive to cooperate less. However, simple tournament analysis has omitted other effects of competitive environments. For example, incentives to incur in unethical behaviors and cheating (Schleifer, 2004; Schwieren \& Weichselbaumer, 2008), and a strong negative effect on the individuals' emotional state (Brandts, Riedl, \& van Winden, 2005).

This article also tries to analyze empirically the effects of cooperative or competitive environ- 
ments on educational outcomes. For this, I use the PISA dataset which includes test score results of students in mathematics, reading and science. Measures of competitive and cooperative attitudes come from questions regarding how much students are concerned about their ranking in the class and how much they help their classmates. Due to the potential endogeneity of these variables, it is necessary to identify an exogenous source of variation which explains individual competitive and cooperative attitudes but that is not correlated with peers' test scores. This exogenous source comes from students' relationships at home; the presence of older, younger and same-age siblings may help explain individual attitudes toward competition and cooperation. However, it is less intuitive to think that these variables would alter peers' cognitive outcomes. For these reasons, I use these variables in an instrumental variables empirical approach. Assuming a non-linear functional form and correcting standard errors, I estimate the effect of a competitive environment on individual test scores. I find empirical support in favor of an inversed U-relationship between academic performance and the degree of competitiveness of the group. This result is similar for mathematics and reading test scores, and robust to different covariates, subsamples and estimation procedures.

Finally, it is important to mention that, despite the fact that there is not much evidence of cooperation or competition decisions on academic outcomes, some authors have focused on the topic. For example, Bigoni et al. (2011) designed an experiment in which incentives are exogenously imposed and students are randomly assigned to three different incentive schemes. A first tournament scheme that fosters competition between students, a cooperative scheme that promotes information sharing and cooperation, and a control treatment in which students neither compete nor cooperate. The authors find that competition induces higher effort levels than cooperation, and that the latter did not show increases in test scores compared to the control group. The problem with this analysis is that the experimental design does not take into account the existence of positive technological externalities 3

Bratti et al. (2008) develop a theoretical model and an empirical analysis similar to those found in this papert They show that free-riding incentives lead to an insufficient degree of

\footnotetext{
${ }^{3}$ Individuals are randomly assigned to each one of the schemes mentioned before and are ex-ante informed about it. They are also randomly assigned to a schoolmate but they don't know his/her identity. During the test, virtual contact information is available in case they decide to communicate between them. This type of cooperative scheme does not internalize positive technological externalities. The presence of these externalities requires communication between students, not at the moment of the test, but when they are studying for it. Under this empirical design, it can be expected that effort levels under the cooperative scheme would be lower. Students perceive their efforts as substitutes and there is no timing for positive externalities to emerge. Then, this result should be addressed with caution due to the incentives design of the authors.

${ }^{4}$ The data analyzed by the authors correspond to PISA (2003). In this paper the empirical analysis is based on PISA (2000). See section 3 for differences and further details.
} 
cooperation between schoolmates. They find empirical evidence that individual competitive attitudes have positive effects on test scores, while student performance increases with average cooperative behavior. Their theoretical model has strong assumptions. In particular, they assume preferences for individual and social learning, where social learning is a public good with the traditional functional forms of individuals' contributions 5 . They conclude that individuals are competitive if time dedicated to individual learning is higher than the one dedicated to the public good. In the case of cooperative behavior, the contrary happens. However, they don't consider preferences for ranking independently from individual test score. Their empirical analysis consists of correlations instead of causal inference. It is important to establish potential endogenous biases that make their estimators inconsistent. In particular, the positive effects of individual competitive attitude can be correlated with unobserved characteristics that explain higher test scores results.

In summary, economic literature has focused on identifying peer effects, but the channels through which they operate are still not clear. This paper tries to identify if they take place through a specific mechanism: cooperation and competition among students. This topic is related to positive technological externalities and individual concerns for relative ranking. Even though cooperative and competitive decisions of students have been analyzed by other authors, conclusions are unclear due to strong theoretical assumptions and the lack of an empirical identification of causality or an incorrect incentive design. Using a theoretical framework with weaker assumptions than those used in the existing literature, this paper identifies how cooperative or competitive attitudes affect cognitive outcomes, and shows a non-linear effect of competition on academic performance. Furthermore, using exogenous variation in peer test scores and competitive attitudes, I present robust empirical evidence supporting the main result of the model.

The rest of this paper is organized as follows: Section 2 develops a simple theoretical framework for explaining potential channels through which competition and cooperation alter educational outcomes. Section 3 presents the data and an empirical strategy using an exogenous source of variation for identifying these effects. Section 4 shows principal empirical results. Section 5 presents a discussion based on the results of the previous sections. Finally, section 6 concludes.

\footnotetext{
${ }^{5}$ They assume that production function of the public good $S$ is given by $\frac{1}{\sigma} * \sum a_{i} * s_{i}$ where $a_{i}$ corresponds to initial abilities of individual $i$ and $s_{i}$ to its contribution. $\sigma$ represents initial ability dispersion of the group. One of their conclusions is that cooperative behavior may emerge if groups are more homogeneous in initial ability distribution. This result is not surprising if you take into account the functional form assumed in the production of the public good and that more homogeneous groups are more efficient in its production.
} 


\section{Theoretical Framework}

This section presents a model aimed at formalizing the channels through which cooperation and competition can alter cognitive outcomes. For this purpose, I will consider the arguments of educational production function, the students' utility functions and their optimal decisions regarding effort and cooperation levels.

\subsection{Educational Production Functions}

Different papers have addressed the arguments of educational production functions? Educational production functions considered in most of these papers are similar to the following:

$$
h_{i}=h(S, Q, C, A, I)
$$

Where $h_{i}$ corresponds to human capital or skills accumulated by individual $i$; $S$ is years of schooling; $Q$ is a vector of school and teachers' characteristics; $C$ is a vector of child characteristics; $A$ is a vector of households' characteristics; and $I$ is a vector of inputs under control of parents. In the economics of education's literature it is usual to assume a household utility function and budget constraints that constitutes a classical optimization problem. Parents' decisions would alter the cognitive outcomes of their children. My approach is different; in particular, I am not considering parents as the main agents. Specifically, the main purpose of this paper is to see how effort decisions of individual $i$ can change and, therefore, my educational production function should include effort as an argument. We also consider different child characteristics, but in order to evaluate peer effects, it is important to add a parameter that captures the initial abilities of individual $i$. The educational production functions should then be of the following type:

$$
h_{i}=h\left(\theta_{i}, e_{i}, X\right)
$$

Where $\theta_{i}$ is a parameter of initial abilities, and $e_{i}$ represents the effort levels of individual $i$. $X$ is a vector of school, teachers, household and other characteristics as described in equation 1. However, this function does not consider peer effects. For this purpose, additional arguments should be included in equation 2. This can be expressed in the following functional form:

$$
h_{i}=h\left(\theta_{i}, k_{i}, \mu_{i}, \theta_{j}, \mu_{j}, X\right) \quad \forall j \neq i
$$

\footnotetext{
${ }^{6}$ See Glewwe \& Kremer (2006), among others.
} 
Equation 3 considers interactions between individual $i$ and individuals $j . \theta_{i}$ and $\theta_{j}$ represent initial abilities' parameters of individual $i$ and individual $j$ respectively. $\mu_{i}$ and $\mu_{j}$ correspond to the parameters through which I will capture peer effects. More precisely, they represent the fraction of time each individual decides to spend studying in group (e.g. cooperating); $k_{i}$ corresponds to the fractions of time each individual decides to spend studying by herself. This can be captured in an additional time constraint:

$$
1=k_{i}+\mu_{i}+l_{i}
$$

Equation 4 says that overall time of individual $i$ (normalized to 1 ) is divided between the time she spends studying individually, the time she spends studying in group and the time she dedicates to leisure. Given the general functional form presented in equation 3 , which has both peer effects and cooperation decisions as arguments, it is important to think in plausible and intuitive assumptions to characterize this function.

Assumption A1. $h(\cdot)$ is a differentiable function. $h_{\theta_{i}}>0, h_{k_{i}}>0, h_{\mu_{i}} \geq 0, h_{\mu_{j}} \geq 0$ and $h_{\theta_{j}} \geq 0 \forall j \neq i$.

Assumption A1 shows that $h$ is an increasing function in the initial ability parameter and the level of individual effort exerted by agent $i$. Similarly, assumption A1 shows the presence of positive externalities due to cooperation decisions. Mainly, human capital accumulated by individual $i$ does not depend negatively on the fraction of time each individual decides to study in group and on the initial ability parameter of individuals $j$. I am explicitly assuming that being with individuals with higher initial abilities or individuals who decide to exert higher levels of cooperation level have positive effects on learning. The next set of assumptions should consider the second derivatives of equation 3 , in order to understand interactions among agents decisions. The following assumption is necessary to guarantee that the problem of individual $i$ is well defined.

Assumption A2. $h_{k_{i}, k_{i}} \leq 0, h_{\mu_{i}, \mu_{i}} \leq 0, \lim _{\mu_{i} \rightarrow 0} h(\cdot)=-\infty, \lim _{\mu_{i} \rightarrow \infty} h(\cdot)=0, h_{\mu_{j}, \mu_{j}} \leq 0$

Assumption A2 presents decreasing or constant marginal returns for all arguments of equation 3. Thus, assumption A2 is necessary for obtaining an internal solution to the individual's maximization problem. However, more important is to characterize how do these marginal returns interact with each other. The following assumption address this issue.

Assumption A3. $h_{k_{i}, \theta_{i}}>0, h_{k_{i}, \mu_{i}}=0, h_{k_{i}, \mu_{j}}=0, h_{k_{i}, \theta_{j}}=0$. 
Assumption A3 states two important things. On the one hand, there is a positive complementarity between individual effort and initial abilities. On the other hand, there is a substitution between individual learning and cooperative or group learning. Specifically, this assumption says that increasing the fraction of time individual $i$ and individual $j$ spend working in group does not increase the marginal return of individual learning. In other words, this assumption explicitly states that there are no complementarities between cooperation and competition in human capital formation. The last element of this assumption states that marginal return of individual effort $\left(k_{i}\right)$ does not depend on the initial ability of other individuals.

Assumption A4. $h_{\mu_{i}, \theta_{i}}>0, h_{\mu_{i}, \mu_{j}}>0, h_{\mu_{i}, \theta_{j}}>0$.

This assumption relates the fraction of time individual $i$ spends studying in group, and the other arguments in educational production function presented in equation 3 . As it can be seen, I am assuming that if individual $i$ and individual $j$ have higher initial abilities, then studying in group (e.g. cooperating) is more efficient. In the same way, the marginal returns to the fraction of time individual $i$ dedicates to group work is higher when individuals $j$ choose a higher level of cooperation $\left(\mu_{j}\right)$.

\subsection{Optimization Problem}

Once established how educational outcomes are produced, it is important to determine how individuals make their decisions. For this purpose it is necessary to address students' utility functions. I will assume that students derive utility from three different terms. The first one corresponds to the absolute human capital accumulated by themselves. The second term is the expected ranking of individual $i$ in the final human capital distribution. Finally, I will assume that students' utility increases with higher levels of leisure. Specifically, I will assume the following functional form:

$$
U_{i}=\bar{w} h_{i}+\gamma R_{i}+f\left(l_{i}\right)
$$

Where $h_{i}$ corresponds to the absolute human capital accumulated by individual $i$ and $\bar{w}$ is a parameter that captures the relative importance of it; $R_{i}$ corresponds to the relative ranking of individual $i$ in the final human capital distribution; $\gamma$, is a parameter that captures utility differentials based on relative ranking. As it can be seen, higher values of $\gamma$ imply that rewards are more dispersed. Thus, individuals have more incentives to compete. Finally, $f\left(l_{i}\right)$ corresponds to the utility derived from leisure time.

Assumption A5. $f(\cdot)$ is a differentiable function, $f_{l_{i}}>0, f_{l_{i}, l_{i}}<0, \lim _{l_{i} \rightarrow 0} f\left(l_{i}\right)=-\infty$ 
Assumption A6. $R_{\natural}^{7}$ is a differentiable function. $R_{i k_{i}}>0, R_{i \mu_{i}} \leq 0, R_{i k_{i}, k_{i}}<0, R_{i \mu_{i}, \mu_{i}}<0$, $\lim _{k_{i} \rightarrow 0} R_{i}(\cdot)=-\infty, \lim _{\mu_{i} \rightarrow 0} R_{i}(\cdot)=-\infty$.

Assumption A5 shows that $f(\cdot)$ is a differentiable, monotonically increasing, concave function on leisure. Assumption A6 states that $R_{i}$ is a differentiable function, that ranking increases with a higher investment in individual effort and that it decreases or remains constant with increases in cooperation levels. It is important to remember that individuals want a higher ranking in order to maximize utility function given by equation 5 . The last two elements of the assumption are necessary in order to find an internal solution to the problem.

Now that the individuals' utility function is determined, it is possible to establish the maximization problem she faces. This problem can be seen by introducing equation 4 in 5

$$
\max _{k_{i}, \mu_{i}} U_{i}=\bar{w} h_{i}+\gamma\left(R_{i}\right)+f\left(1-k_{i}-\mu_{i}\right)
$$

An equilibrium in this problem is constituted by a pair $\left(k_{i}^{*}, \mu_{i}^{*}\right)$ for each individual. The first order conditions of this problem are given by the following equations:

$$
\begin{aligned}
& {\left[k_{i}\right]: \bar{w} \frac{\partial h_{i}}{\partial k_{i}}+\gamma \frac{\partial R_{i}}{\partial k_{i}}-\frac{\partial f}{\partial l_{i}}=0} \\
& {\left[\mu_{i}\right]: \bar{w} \frac{\partial h_{i}}{\partial \mu_{i}}+\gamma \frac{\partial R_{i}}{\partial \mu_{i}}-\frac{\partial f}{\partial l_{i}}=0}
\end{aligned}
$$

Assumptions A1 to A6 guarantee an internal solution to the problem. The first term of equation 7 shows the marginal benefit of increasing individual effort $k_{i}$. As it can be seen, this marginal benefit increases when the exogenous parameter $\bar{w}$ is higher and when differential due to relative ranking $(\gamma)$ is also higher. The second term of equation 7 represents the marginal cost of increasing individual effort. This marginal cost is represented by the time of leisure she loses when studying.

Similarly, the first term of equation 8 shows the marginal benefit of increasing group effort. However, increasing this effort has two possible costs. The first one is associated to the increase of human capital accumulated by individual $j$ which reduces the differential gap between both agents. The second one is the cost associated to the leisure loss.

\footnotetext{
${ }^{7}$ Future research will focus on identifying a functional form that relates human capital accumulated by the whole group and relative position. See Mejía \& St-Pierre (2008) for an example.
} 


\subsection{Comparative Statics}

It is now important to analyze how these decisions are modified by changes in the parameters of the model. Specifically, our principal parameter of interest is the competition parameter $(\gamma)$. In particular, I am interested in studying how does human capital accumulated by both individuals change if the level of competition between the agents is higher.

Proposition P1. If $\gamma_{1}<\gamma_{2} \Rightarrow k_{1, i}<k_{2, i}$. Higher values of $\gamma$ increase individual effort $k_{i}$.

Proof: If $\gamma_{1}<\gamma_{2} \Rightarrow k_{1, i}<k_{2, i}$

Suppose by contradiction that $k_{1, i} \geq k_{2, i}$. Then, the two following inequalities hold:

$\operatorname{Pr}$ 1. $U\left(\gamma_{1}, k_{1, i}, \cdot\right) \geq U\left(\gamma_{1}, k_{2, i}, \cdot\right)$

Pr 2. $U\left(\gamma_{2}, k_{1, i}, \cdot\right) \leq U\left(\gamma_{2}, k_{2, i}, \cdot\right)$

From inequality 1 we have that:

$\bar{w} h\left(k_{1, i}, \mu_{i}, \cdot\right)+\gamma_{1} R_{i}\left(k_{1, i}, \mu_{i}, \cdot\right)+f\left(1-k_{1, i}-\mu_{i}\right) \geq \bar{w} h\left(k_{2, i}, \mu_{i}, \cdot\right)+\gamma_{1} R_{i}\left(k_{2, i}, \mu_{i}, \cdot\right)+f\left(1-k_{2, i}-\mu_{i}\right) \rightarrow$

Pr 3. $\gamma_{1}\left(R_{i}\left(k_{1, i}, \mu_{i}, \cdot\right)-R_{i}\left(k_{2, i}, \mu_{i}, \cdot\right)\right) \geq \bar{w}\left(h\left(k_{2, i}, \mu_{i}, \cdot\right)-h\left(k_{1, i}, \mu_{i}, \cdot\right)\right)+f\left(1-k_{2, i}-\mu_{i}\right)-f\left(1-k_{1, i}-\mu_{i}\right)$

From inequality 2 we have that:

$\bar{w} h\left(k_{1, i}, \mu_{i}, \cdot\right)+\gamma_{2} R_{i}\left(k_{1, i}, \mu_{i}, \cdot\right)+f\left(1-k_{1, i}-\mu_{i}\right) \leq \bar{w} h\left(k_{2, i}, \mu_{i}, \cdot\right)+\gamma_{2} R_{i}\left(k_{2, i}, \mu_{i}, \cdot\right)+f\left(1-k_{2, i}-\mu_{i}\right) \rightarrow$

$\operatorname{Pr} 4 . \gamma_{2}\left(R_{i}\left(k_{1, i}, \mu_{i}, \cdot\right)-R_{i}\left(k_{2, i}, \mu_{i}, \cdot\right)\right) \leq \bar{w}\left(h\left(k_{2, i}, \mu_{i}, \cdot\right)-h\left(k_{1, i}, \mu_{i}, \cdot\right)\right)+f\left(1-k_{2, i}-\mu_{i}\right)-f\left(1-k_{1, i}-\mu_{i}\right)$

From inequalities 3 and 4 we have that:

Pr 5. $\gamma_{2}\left(R_{i}\left(k_{1, i}, \mu_{i}, \cdot\right)-R_{i}\left(k_{2, i}, \mu_{i}, \cdot\right)\right) \leq \gamma_{1}\left(R_{i}\left(k_{1, i}, \mu_{i}, \cdot\right)-R_{i}\left(k_{2, i}, \mu_{i}, \cdot\right)\right)$

Due to the fact that $R_{i}$ is an increasing function in $k_{i}$ and that $k_{1, i} \geq k_{2, i}$, then $R_{i}\left(k_{1, i}, \mu_{i}, \cdot\right) \geq$ $R_{i}\left(k_{2, i}, \mu_{i}, \cdot\right)$ which implies that $\gamma_{2} \leq \gamma_{1}$. This is a contradiction. Then, $k_{1, i}<k_{2,1}$.

Proposition P2. If $\gamma_{1}<\gamma_{2} \Rightarrow \mu_{1, i} \geq \mu_{2, i}$. Higher values of $\gamma$ decrease group effort $\mu_{i}$.

Proof: If $\gamma_{1}<\gamma_{2} \Rightarrow \mu_{1, i} \geq \mu_{2, i}$

Suppose by contradiction that $\mu_{1, i}<\mu_{2, i}$. Then, the two following inequalities hold:

Pr 6. $U\left(\gamma_{1}, \mu_{1, i}, \cdot\right) \geq U\left(\gamma_{1}, \mu_{2, i}, \cdot\right)$

$\operatorname{Pr}$ 7. $U\left(\gamma_{2}, \mu_{1, i}, \cdot\right) \leq U\left(\gamma_{2}, \mu_{2, i}, \cdot\right)$

From inequality 6 we have that: $\bar{w} h\left(k_{i}, \mu_{1, i}, \cdot\right)+\gamma_{1} R_{i}\left(k_{i}, \mu_{1, i}, \cdot\right)+f\left(1-k_{i}-\mu_{1, i}\right) \geq \bar{w} h\left(k_{i}, \mu_{2, i}, \cdot\right)+\gamma_{1} R_{i}\left(k_{i}, \mu_{2, i}, \cdot\right)+f\left(1-k_{i}-\mu_{2, i}\right) \rightarrow$ 
Pr 8. $\gamma_{1}\left(R_{i}\left(k_{i}, \mu_{1, i}, \cdot\right)-R_{i}\left(k_{i}, \mu_{2, i}, \cdot\right)\right) \geq \bar{w}\left(h\left(k_{i}, \mu_{2, i}, \cdot\right)-h\left(k_{i}, \mu_{2, i}, \cdot\right)\right)+f\left(1-k_{i}-\mu_{2, i}\right)-f\left(1-k_{i}-\mu_{1, i}\right)$

From inequality 7 we have that:

$\bar{w} h\left(k_{i}, \mu_{1, i}, \cdot\right)+\gamma_{2} R_{i}\left(k_{i}, \mu_{1, i}, \cdot\right)+f\left(1-k_{i}-\mu_{1, i}\right) \leq \bar{w} h\left(k_{i}, \mu_{2, i}, \cdot\right)+\gamma_{2} R_{i}\left(k_{i}, \mu_{2, i}, \cdot\right)+f\left(1-k_{i}-\mu_{2, i}\right) \rightarrow$

Pr 9. $\gamma_{2}\left(R_{i}\left(k_{i}, \mu_{1, i}, \cdot\right)-R_{i}\left(k_{i}, \mu_{2, i}, \cdot\right)\right) \leq \bar{w}\left(h\left(k_{i}, \mu_{2, i}, \cdot\right)-h\left(k_{i}, \mu_{1, i}, \cdot\right)\right)+f\left(1-k_{i}-\mu_{2, i}\right)-f\left(1-k_{i}-\mu_{1, i}\right)$

From inequalities 8 and 9 we have that:

Pr 10. $\gamma_{2}\left(R_{i}\left(k_{i}, \mu_{1, i}, \cdot\right)-R_{i}\left(k_{i}, \mu_{2, i}, \cdot\right)\right) \leq \gamma_{1}\left(R_{i}\left(k_{i}, \mu_{1, i}, \cdot\right)-R_{i}\left(k_{i}, \mu_{2, i}, \cdot\right)\right)$

Due to the fact that $R_{i}$ is a decreasing function in $\mu_{i}$ and that $\mu_{1, i}<\mu_{2, i}$, then $R_{i}\left(k_{i}, \mu_{1, i}, \cdot\right) \geq$ $R_{i}\left(k_{i}, \mu_{2, i}, \cdot\right)$ which implies that $\gamma_{2} \leq \gamma_{1}$. This is a contradiction. Then, $\mu_{1, i} \geq \mu_{2,1}$.

The intuition behind $\mathrm{P} 1$ is that when $\gamma$ is higher, there are more incentives for individuals to compete. As the differential due to competition increases there is a higher incentive to increase the levels of individual effort in order to have a higher ranking. Proposition P2 states that when competition is higher individuals decrease group work. The intuition behind this result is that the higher the differential between both agents is, the higher are the costs of increasing group effort. Both propositions lead to the following result:

Proposition P3. There is an internal optimal value of $\gamma$ that maximizes $\sum_{l=1}^{N} h_{l}$

Proof: $\frac{\partial \sum_{l=1}^{N} h_{l}}{\partial \gamma}=\sum_{l=1}^{N} \frac{\partial h_{l}}{\partial k_{l}} \frac{\partial k_{l}}{\partial \gamma}+\sum_{l=1}^{N} \sum_{k=1}^{N} \frac{\partial h_{k}}{\partial \mu_{l}} \frac{\partial \mu_{l}}{\partial \gamma}$

The first term represents the marginal benefit of increasing $\gamma$, it is the increase in human capital accumulated by the whole group due to the increases in individual effort of all individuals. The second term represents the marginal costs of increasing $\gamma$; namely, the decreases in human capital accumulated by the group due to the reductions of cooperation levels between agents. Given the assumptions it is possible to conclude the existence of an optimal competition value $(\gamma)$ that maximizes overall academic performance. Then, there is a trade-off between competition and cooperation in human capital formation. Now we turn to the empirical strategy in order to test the main prediction of the model; namely, the existence of an internal optimal level of competition, and the presence of positive technological externalities in educational production functions, taking into account that individuals based their decisions on the absolute value of human capital accumulated by her, and her position in the ranking.

\section{$3 \quad$ Data and Empirical Strategy}

The data used for the empirical exercise comes from the international database of the OECD Programme for International Student Assesment (PISA) of 2000. In PISA (2000), fifteen-year 
old students from participating countries are evaluated in three different areas: mathematics, reading and science 8 . This allows me to have comparable test scores across students given that they take the same test in all of the areas. The data consists of a cross section data base in which we can see academic performance for each student. Besides test score results, PISA contains information of children, household and school characteristics. Two additional questionnaires are answered by students at the moment they take the test. This allows me to add covariates and diminish potential omitted variables biases. In addition to student's questionnaires, PISA (2000) has a school questionnaire answered by school's principals. This allows me to add school controls which also affect educational outcomes. Thus, I am able to control for different characteristics which are arguments of the educational production function.

In addition to this information, a questionnaire of cross-curricular competencies is available. In this questionnaire, information about preferences on ranking and group work are identified. In particular, students answer whether they agree or disagree with a list of statements in the questionnaire9. For ranking preferences I use the students' level of agreement with the following statement: "I like to try to be better than other students". I construct two different measures of competitive attitudes at the student level. The first measure is a dummy equal to one if students agree or agree somewhat with the mentioned statement, I will call this variable better 1 . The second measure is equal to one only if the student agrees with such statement. This variable is named better ${ }_{2}$. For cooperative preferences I use the statement of how much they like to help other people do well in a group. Similarly to competitive attitudes I construct two measures for cooperative attitudes. The variable help $p_{1}$ is a dummy equal to one if students agree or agree somewhat with the statement, and equal to zero otherwise. The second measure, called help $p_{2}$, is a dummy equal to one if the student agrees with the statement and zero otherwise.

Apart from the statements chosen for the measures I developed, there are other questions related to competitive and cooperative attitudes. PISA (2000) data base contains competitive and cooperative learning indexes based on these questions ${ }^{10}$. The problem of using this information is that it contains elements which correspond to students' decisions instead of cooperative or competitive preferences. For example, the competitive index includes the question that asks whether students learn more if they try to do better than their classmates. Even though this information is related with competitive attitudes, it corresponds to an outcome based on students' effort decisions. Therefore, including them in the analysis would be problematic given

\footnotetext{
${ }^{8}$ Science tests are only available in a subsample of the data.

${ }^{9}$ There are four possible answers: 1. Disagree 2. Disagree somewhat 3. Agree somewhat 4. Agree.

${ }^{10}$ There is a positive and significant correlation between these indexes and main independent variables used in this paper. Furthermore, results are robust if competition measures are constructed based on these indexes.
} 
that preferences and agents' decisions won't be differentiated in the empirical analysis.

PISA tests have been applied every two years since 2000. However, cooperative and competitive attitude questions are only available for 2000 and 2003. For 2003, these questions are specific to the area of mathematics. Due to a change in the questions' wording and the lack of information for other years, empirical exercises are carried out only for the 2000 data. Finally, the cross-curricular competencies questionnaire is only available for a subsample of participant countries. Then, our empirical analysis will focus only on those countries that have this information available11

It is important to mention that questions used to construct cooperative and competitive attitudes are not mutually exclusive. Hence, one student can agree that she tries to perform better than others and that she likes others to do well in the group. However, as I explained before, I'm not interested in cooperation or competition alone, but in how are they related, this is why, it is necessary to construct measures of competition in which there exists a trade-off between competitive and cooperative decisions. Specifically, $\gamma$ captures the relative importance of competitive attitudes. Then, our variable of interest is the proportion of competitive attitudes relative to cooperative ones in a given group. Using the proportion of these constructed variables allows me to construct these relative measures. Competition Com $=\frac{\text { Group }_{\text {betters }}}{\text { Group betters }_{\text {S }} \text { Grouphelps }}$ for $s=$ 1,2, where Groupbetter corresponds to the fraction of individuals in the group $g$ for whom the variable better $r_{s}$ is equal to one, and Group help $_{s}$ to the fraction of students for whom the variable $h e l p_{s}$ is equal to one. With these variables it is possible to construct a measure of the degree of competitiveness in a given group. The following equation shows the relationship to be estimated:

$$
\begin{aligned}
y_{i, h, g, s, c}= & \beta f\left(\text { competition }_{g, s, c}\right)+\alpha_{1} C_{i, h, g, s, c}^{\prime}+\alpha_{2} H_{h, g, s, c}^{\prime} \\
& +\alpha_{3} E_{g, s, c}^{\prime}+\alpha_{4} S_{s, c}^{\prime}+\eta_{c}+\varepsilon_{i, h, g, s, c}
\end{aligned}
$$

Where $y_{i, h, g, s, c}$ corresponds to the educational outcome of individual $i$, of household $h$, belonging to group $g$ in school $s$ in country's region $c . f\left(\right.$ competition $\left._{g, s, c}\right)$ is a flexible functional form of competitive environments generated by other members of the same group. Motivated by the theoretical model, I am assuming a non-linear functional form of competition on academic performance. $C_{i, h, g, s, c}^{\prime}$ is a vector of child characteristics; $H_{h, g, s, c}^{\prime}$ a vector of household characteristics; $E_{g, s, c}^{\prime}$ are characteristics of the environment of the group such as discipline and good relations with teachers; $S_{s, c}^{\prime}$ is a vector of school characteristics. All these vectors correspond

\footnotetext{
${ }^{11}$ Countries for which competitive and cooperative questions are available include: Albania, Austria, Belgium, Brazil, Bulgaria, Chile, Czech Republic, Denmark, Finland, Germany, Hong Kong, Hungary, Ireland, Israel, Italy, Republic of Korea, Latvia, Liechtenstein, Luxembourg, Mexico, Netherlands, New Zealand, Norway, Portugal, Romania, Russian Federation, Sweden, Switzerland, Thailand, Macedonia, United Kingdom and United States.
} 
to arguments of the educational production function presented in section 2.1 and introduced in equation 1. $\eta_{c}$ is a country-region fixed effect that captures characteristics of this geographic unit that can alter educational outcomes, and $\varepsilon_{i, h, g, s, c}$ is an error term. Tables 1 and 2 present summary statistics of test scores, competition variables, and covariates included in equation 9 , and figure 1 test scores distribution for mathematics and reading.

Deriving empirical conclusions in this setting has two main problems. The first one is potential endogeneity presented in competitive attitudes due to self-selection. The second problem is the functional form of the effect of competition over test scores. In order to solve the first problem, I propose an instrumental variables estimation. For the second one, it is necessary to assume a particular functional form. Given the theoretical results, I am assuming a quadratic functional form, which will show an inversed U-relationship between group competition and educational outcomes. This functional form is motivated by the theoretical conclusions. Additionally, I perform a non-parametric regression in order to evaluate if this functional form is appropriate.

The main problem in estimating equation 9 is that different sources of endogeneity can bias the coefficients of interest. The first one, as mentioned in section 1, corresponds to selection bias: the allocation to each one of the groups can be correlated with unobserved characteristics not included in the vector $X_{i,-i, h, s, p, c}^{\prime}$. For example, individuals with higher initial ability parameters can become more competitive due to higher academic standards. Thus, competitive environments can be correlated with higher initial abilities. Hence, estimation of equation 9 is biased. In order to solve these issues, it is necessary to identify an exogenous source of variation that explains competition environments within a given group, but that is not correlated with individual $i^{\prime} s$ educational outcomes. For this purpose I will use the variation coming from the presence of younger, older and no siblings in the others children's households ${ }^{12}$. There are intuitive reasons pointed out by economic literature to support the presence of positive and negative externalities for having siblings. For example Knoef \& Kooreman (2011) develop a structural model to show how the presence of siblings affects cooperative and competitive decisions within the household. There are intuitive reasons to think that daily contact and resource-sharing positively influence pro-social behavior, or that competition for parents' time and economic resources will increase competition in the classroom. Then, it is expected that individuals with younger, older, same-age or no siblings have different competitive or cooperative attitudes. However, it is not intuitive to think that individual educational outcomes may be affected by the presence

\footnotetext{
${ }^{12}$ It is important to state that I am adding the presence of these siblings in each student's own household as covariates.
} 
of siblings in classmates' households. Due to these reasons, I will use the fraction of students for each group who has older, younger, same age or no siblings in a first stage estimation which predicts exogenous values of competition levels. The following equations show the parameters to be estimated:

$$
\begin{gathered}
\text { Competition }_{g, s, c}=\delta_{0}+\delta_{1} \text { group younger }_{g, s, c}+\delta_{2} \text { group }_{\text {older }}, s, c \\
+\delta_{3} \text { group same }_{\text {age }}, s, s+\delta_{4} \text { no } \text { siblings }_{g, s, c}+\Delta^{\prime} X+\varepsilon_{i, g, s, c}
\end{gathered}
$$

Where Competition ${ }_{g, s, c}$ corresponds to the competition measure previously described and faced by individuals in the same group; group younger ${ }_{g, s, c}$, group $_{\text {older }}^{g, s, c}$, group same age $_{g, s, c}$, and no siblings $s_{g, s, c}$ are the fraction of the group who has younger, older, same age, and no siblings respectively; $X$ corresponds to a vector of covariates (the same as those presented in equation 9p; finally, $\varepsilon_{i, g, s, c}$ is an error term. Using the predict values of equation 10 in equation 9. I am able to identify an exogenous source of variation of competition levels faced by each student in order to identify the effect of competition on academic performance.

\section{Results}

Figure 2 presents a visual motivation of the question addressed in this paper. The graph shows the mean test score for each area of knowledge for each competition leve ${ }^{13}$. The graph shows that for lower competition levels, increases in competition generate positive effects on educational outcomes. However, for higher levels of it, it has a detrimental effect. Specifically, this result is consistent for the three areas of knowledge. Even though this result is interesting it does not represent any formal analysis that tests the main hypothesis presented in the previous section.

OLS estimations for equation 9 for mathematics and reading test scores are presented in table 3 for measure 1 of competition 14 . Column 1 presents a correlation between competition and test scores, column 2 adds individual covariates, column 3 household characteristics, column 4 region fixed effects, column 5 school environment covariates and column 6 school characteristics. As it can be seen, there are two effects in opposite directions. On the one hand, there is a positive significant effect of the linear term. An increase in one percentage point of competition increases mathematic test scores between 0.006 and 0.010 standard deviations, and reading test scores

\footnotetext{
${ }^{13}$ We define competition as the fraction of individuals who compete relative to those who cooperate in the group. Specifically, Competition $=\frac{\sum \text { better }_{1}}{\sum \text { better } 1+\text { help }_{1}}$

${ }^{14}$ Results for science test scores are weaker. For the second measure of competition, I also find a non linear effect of competition on academic performance. These results are no presented due to space reasons, but available upon request.
} 
between 0.004 and 0.008 standard deviations. On the other hand, there is a negative significant effect of the quadratic term. Estimations show an effect between -0.008 and -0.014 standard deviations for mathematics, and between -0.009 and -0.014 standard deviations for reading test scores.

In addition, the table presents the optimal level of competition that maximizes academic test scores for each one of these estimation 15 . It can be seen that there is an internal solution for the optimal value of competition that maximizes academic performance. This value range between 0.318 and 0.401 for mathematic test score and between 0.168 and 0.34 for reading test score. In the same way, the table presents two hypotheses for evaluating the existence of an internal optimal value of competition. The first one, is that $\gamma=0$ which represents that in proportion everyone cooperates and nobody competes. The second one is $\gamma=1$ which represents the opposite. The table shows that in all specifications for both, mathematics and reading test scores, it is possible to reject the null hypothesis that this value is equal to zero or equal to one. Then, it is possible to conclude the existence of an internal value of competition that maximizes academic performance. In general, we find that in order to maximize human capital accumulated by the group, students should study individually only the $40 \%$ for mathematics and the $36 \%$ for reading of the whole time they dedicate to study.

One possible problem of the empirical results presented in table 3 is the functional form I am assuming on the effect of competition on academic performance. In order to show the pertinence of this functional form, I perform a non parametric estimation, specifically, a local linear regression of this effect. The results can be seen in figure 3 . The graph shows that a quadratic functional form with the signs of the linear and the quadratic term of table 3 is appropriate. In particular, the graph shows an inversed U-relationship between competition and academic performance for mathematics test scores, which is consistent with the empirical results found for the quadratic functional form.

Even though, these estimations suggest that the theoretical conclusions derived in section 2 actually operate, it is necessary to consider potential endogeneity issues as were described in the previous section. In order to diminish this endogeneity, I propose an instrumental variables estimation using children's interactions at home as an exogenous source of variation for competition between students. Then, the first step is to test whether having older, younger, same age or no siblings is correlated with cooperative and competitive decisions in the classroom. Table 4 presents first stage estimations for the linear and the quadratic term of competition using as

\footnotetext{
${ }^{15}$ Optimal values of competition are denoted $\gamma$ and equal to $\frac{\beta_{1}}{2 \beta_{2}}$
} 
instruments the fraction of the classroom who has no siblings and those who has older siblings $\AA^{16}$. The results are robust and similar throughout all empirical specifications. In general, column 6 shows that an increase in one percentage point in the fraction of students with no siblings increases the linear term of competition in 0.00025 points and the quadratic term in 0.00022 points respectively. We find the opposite, but weaker relationship between the proportion of children who has older siblings and competition variables. Specifically a negative effect on the linear term and a positive one on the quadratic term. Even though this effect is not significant in column 6 it is similar to estimations in other specifications. It can be concluded from these results that only children are relatively more competitive than their peers, which reflects in higher values of competition faced by the students of their class-rooms. Finally, the table presents the F-test for excluded instruments. The null hypothesis of this test is that instruments' coefficients are equal to zero. As it can be seen, for both the linear and the quadratic term the F-test is higher than ten which means that these instruments explain the endogenous variables and are jointly statistically significant. Thus, they are relevant enough to be considered as good instruments for competition.

The next step is to estimate the relationship between competition and academic performance using the instrumental variables approach. Results for the first measure of competition on mathematics and reading test scores are presented in table 5 . As it can be seen, the coefficients of both, the linear and the quadratic term are significantly higher in absolute terms. Panel A shows the results for the mathematics test scores. The results show that an increase in one percentage point of competition level increases mathematics test scores in approximately 0.709 standard deviations linearly and decreases this same test score in 0.772 standard deviations quadratically. This results are consistent with the idea of a nonlinear effect of competition over academic performance. Similarly, panel B presents the results for reading test scores. Like mathematics I find a positive effect of the linear term of 0.746 standard deviation and a negative effect of the quadratic term of 0.768 standard deviations in column 6 .

It is important to explain the reasons why coefficients of both, the linear and the quadratic terms, are higher. An instrumental variables empirical strategy is a local estimation over those competition levels that vary due to changes in the instruments. The values of the predicted competition variable range between 0.35 and 0.55 , as it can be seen in figure 4 , then this result is a local estimation of a predicted variable with standard deviation significant lower than the original competition variable. Furthermore, the table shows that the optimal competition

\footnotetext{
${ }^{16}$ Results are robust to different combinations of the initial four instruments.
} 
values don't change too much from the OLS estimation of table 3 to the IV estimation of table 5. Specifically, with the instrumental variables approach, I find that the optimal values of competition are approximately equal to 0.449 for mathematics and 0.486 for reading test scores respectively. This means that only the $44 \%$ and $48 \%$ of the students who compete and cooperate should compete in order to maximize mathematics and reading test scores of the whole group. The table 5 also shows the hypotheses that this optimal value is equal to zero or equal to one. Most of all specifications, excepting column 2, show that both null hypothesis can be rejected at $5 \%$ of significance level. Then, it can be concluded the existence of an internal competition value that maximizes total academic performance as it is predicted by proposition $\mathrm{P3}$.

In addition to these results, table 5 presents the endogeneity test of the competition in the empirical specification of equation 9. The null hypothesis of this test is that the variable of interest is exogenous. The results show that in all the six columns and for both, mathematics and reading test scores, it is possible to reject this null hypothesis. Thus, it is possible to conclude that an instrumental variables empirical strategy is good. In the same way, I present the Hansen statistic for testing if the instruments are effectively exogenous 17 . The null hypothesis is that both instruments effectively are. The table shows that for both, mathematics and reading, it is only possible to reject this null hypothesis in the columns 1 and 2 . Then, it can be concluded that when enough covariates are added the presence or absence of siblings in classmates' household is exogenous to individual academic performance. Finally, figure 4 presents a non-parametric estimation of the predicted values of competition on academic performance. As it can be seen in the graph, there is strong evidence that the quadratic functional form I am assuming is appropriate to estimate this relationship 18

Hither to, two different empirical strategies are consistent with the theoretical results derived in section 2. An OLS and an IV strategies show a non linear effect of competition over academic performance and the existence of an internal optimal value of competition in order to maximize human capital accumulated by the whole group. It is important to think if the intuitive arguments of the theoretical model are consistent with this result. My main argument is technological due to the presence of positive externalities in educational production functions. If this is the channel through which competition may have a detrimental effect over test scores results, then it is expected that the optimal competition values for those in the lower part of

\footnotetext{
${ }^{17}$ For doing these tests it is necessary to include more instruments than endogenous variables. I am adding the fraction of the group who has younger siblings.

${ }^{18}$ The predicted values of a first stage have to be used linearly in a second stage. Other functional form biased the coefficients. This is known as the forbidden regression problem. However this graphic show intuitively that it is correct to assume a quadratic functional form.
} 
the test scores distribution are lower than those of the higher parts. This, due to the fact that the ones who benefit the most of these externalities are the former ones.

Table 6 shows the optimal competition values for mathematics and reading test scores, separating the sample between those students above and below the median value of the dependent variable, for an OLS estimation. The competition variable is constructed using the answers of all students in a group. As it can be seen, in most of all the specifications, and for both areas, the optimal competition values are lower for those below the median value. This is consistent with the presence of positive technological externalities in educational production functions. In column 6, panel $\mathrm{A}$ and $\mathrm{B}$ of table 6 show that the optimal competition value for mathematics for those below the median is equal to 0.32 , while for those above is equal to 0.43. Furthermore, it can be seen that the null hypothesis that the optimal value of competition $\gamma$ is equal to zero or to one is rejected for students below the median, but it can't be rejected for those above. For reading test scores, that corresponds to panel $\mathrm{C}$ and $\mathrm{D}$ of table 6 , the results I find are very similar. In particular, column 6 shows an optimal value of 0.21 for those below and of 0.35 for those above. However, both null hypotheses can be rejected for all groups through all specifications.

The same result using an IV approach is presented in table 7 . The table shows the same pattern of the OLS estimations of table 6. However, optimal values of competition are slightly higher. For those below the median of the dependent variable is approximately equal to 0.41 and for those above 0.52 , as can be seen in column 6 of table 7 in panels $\mathrm{A}$ and $\mathrm{B}$. The null hypothesis that this optimal value is equal to one can be rejected for those below the median value, but not for those above. Results for reading test scores, in panels $\mathrm{C}$ and $\mathrm{D}$, show the same pattern of lower optimal competition values for those in the left part of test scores distribution. However, standard errors of these values are higher for this group.

In summary, two different empirical strategies, an OLS and an IV, are consistent with proposition $\mathrm{P3}$ of the theoretical model presented in section 2: the existence of an internal optimal value of competition in order to maximize human capital accumulated by the whole group. We find strong evidence of the presence of positive technological externalities separating the sample between those in the higher and the lower parts of the test scores distribution. This result verifies the intuitive arguments presented in the theoretical model, and the presence of positive technological externalities in educational production functions. 


\section{Discussion}

The allocation of students has been one important topic for parents, schools and policy makers. Given the fact that peer effects exist, it is important to establish how groups must be conformed in order to maximize each student's potential. This paper shows that it is important not only how they are allocated, but also how incentives are designed in order to maximize educational outcomes and interactions among students. The parameter and variable of interest in this paper was competition between the members of a group. Even tough this parameter is given by students' utility functions, it is important to notice that teachers, funding systems and scholarship programs, and university and college admissions processes have direct impact on how these preferences are modified.

Specifically, teachers can modify students' preferences through grading systems. There is no clear evidence on what conditions influence some grading systems to be more efficient than other: 19 . However this paper presents insights about it. In general, we can find three different grading systems. First, systems where student grades depend exclusively on their individual performance on academic tests. Second, systems promoting group work and cooperation among students, in which grades are the result of aggregated decisions of group members. Finally, a third grading system, based on relative positions occupied by students in their group, also called a tournament grading system. Those grading systems are related to the competition level students are facing. In particular, systems based on individual performance are neutral because grades are not affected by peers. In the same way, systems encouraging group work can be interpreted as cooperative ones, in which all members of a particular group have the same grade. Analogously, tournament grading systems, in which individuals show concern for their ranking, constitute competitive systems due to inequalities in students' grades. Thus, teachers can modify individual preferences through changes in the grading system.

School financing, scholarship programs, and college and university admissions processes should consider results derived in this paper for a specific reason: increasing competition levels between students beyond a certain level can diminish human capital accumulation. This is related to incentives generated by the educational system. Specifically we should wonder how hu-

\footnotetext{
${ }^{19}$ Literature has shown evidence favoring cooperative systems over neutral ones. Aliye \& Erdem (2009) finds positive effects of cooperation in test scores and other variables such as: positive relations between different ethnics, mutual concern between students and self-esteem. In the same way, evidence in high schools has been found (Astin, 1993; Kadel et al., 1992; Johnson et al., 1991).In relation to higher education, Yamarik (2007) show higher test scores in macroeconomic test scores of students who work in group. In the other hand, it is not clear which system is most efficient between neutral systems and competitive ones. Becker \& Rosen (1992) argue that competition among students increases effort if that effort is rewarded. Under this perspective, if loss risk is too high, individual effort can diminish.
} 
man capital accumulated and test scores results are modified if we change students preferences. This paper shows that at some points increasing concerns for rankings would be negative for educational outcomes, especially for those in the lower percentiles of the initial ability distribution, as they do not benefit from the positive externalities of cooperation from their peers.

An additional important point is that this article only considers a mechanism in which cooperative attitudes from students affect learning: technological positive externalities in educational production functions. However, it is important to point out that cooperative attitudes from students can positively alter other factors in the production of learning. In general, cooperative or pro-social actions in a classroom can be reflected in better relationships among students and higher levels of confidence and self-esteem. Taking these elements into account and the effect they can have over learning, it would be important to determine what is the optimal level of competition between individuals that maximizes human capital acquired by a particular group.

\section{Conclusions}

Most economic analyses of peer effects have focused on empirical strategies that allow for an unbiased estimation of these effects. Nevertheless,empirical evidence on the mechanisms through which they operate is still scarce. Some have pointed out the importance of different agents, their decisions and their effects on educational outcomes. This article considers a direct mechanism in which peers can affect a student's educational outcomes: cooperation and competition between them. A theoretical analysis shows that individual effort levels depend positively on individual concern for ranking and cooperation levels depend negatively on the same dimension. The existence of positive technological externalities in educational production functions and the importance of individual effort decisions in educational outcomes reflect in the existence of an optimal level of competition for maximizing total human capital accumulated by the group. Using data from PISA (2000) in which students are tested in mathematics, reading and sciences, and in which they report cooperation and competition preferences, I find empirical evidence that supports the theoretical conclusion.

The main aim of this paper is to show a non-linear effect of competition on educational outcomes. I find robust evidence of an inversed U-relationship between competition and academic performance. Specifically, I find an internal optimal value of competition that maximizes academic results. However, this paper does not focus on the determinants of this optimal value. In particular, it is important to analyze how this optimal value depends on the parameters of the initial ability distribution of the group. Future research will focus on this topic. 
I expect to find a negative relationship between optimal competition level and the mean of the initial ability distribution. Positive externalities on educational production functions should be higher for groups with a greater initial ability mean. Then, it is necessary to encourage more cooperative attitudes among the members of these groups. I also want to find a relationship with initial ability dispersion. I expect an inversed U-relationship between optimal level of competition and this parameter. The reasons for this relationship is that, Mejía \& St-Pierre (2007) hold that, under tournament systems individuals exert higher levels of effort if the group they are competing with is more homogeneous. Then, if the degree of competition is constant increases in ability dispersion would have a detrimental effect on individuals' effort levels. To compensate this negative effect, the optimal competition level should be higher. However, if this dispersion is too high, individuals perceive that changes in effort levels would not change their relative ranking, and then, increases in competition would only diminish positive externalities. Due to these reasons, it is necessary to decrease optimal competition level to obtain increases in the positive externalities of educational production functions.

In conclusion, this paper tries to determine one possible mechanism through which peer effects operate: cooperation and competition between classmates. It is possible to show the existence of positive technological externalities between group members, due to the fact that increases in competitive attitudes or concern for ranking can have a detrimental effect on learning. This is particularly important, not only for the allocation of students but also for the mechanism designs which can alter their preferences. It can be concluded that it is important to establish a correct design of grading systems and incentives within the educational system. Finally, it is essential to analyze the benefits and costs in terms of educational outcomes resulting from increases in competitive preferences. This should be a concern for parents, teachers, schools and policy makers. 


\section{References}

Aliye, \& Erdem. (2009). Preservice teachers attitudes towards cooperative learning in mathematics course. Procedia - Social and Behavioral Sciences, 1(1), 1668 - 1672.

Astin, A. W. (1993). What matters in college: Four critical years revisited. Jossey-Bass.

Becker, W. E., \& Rosen, S. (1992). The learning effect of assessment and evaluation in high school. Economics of Education Review, 11(2), 107-118.

Bigoni, M., Fort, M., Nardotto, M., \& Reggiani, T. (2011). Teams or tournaments? a field experiment on cooperation and competition in academic achievement (Working Papers No. wp752). Dipartimento Scienze Economiche, Universita' di Bologna.

Brandts, J., Riedl, A., \& Winden, F. van. (2005). Competition and well-being (IZA Discussion Papers No. 1769). Institute for the Study of Labor (IZA).

Bratti, M., Checchi, D., \& Filippin, A. (2008). Should you compete or cooperate with your schoolmates? (IZA Discussion Papers No. 3599). Institute for the Study of Labor (IZA).

Brunello, G., Paola, M. D., \& Scoppa, V. (2009). Peer effects in higher education: Does the field of study matter? (Tech. Rep.).

Dills, A. K. (2005). Does cream-skimming curdle the milk? a study of peer effects. Economics of Education Review, 24 (1), 19-28.

Duflo, E., Dupas, P., \& Kremer, M. (2008). Peer effects, teacher incentives, and the impact of tracking: Evidence from a randomized evaluation in kenya (NBER Working Papers No. 14475). National Bureau of Economic Research, Inc.

Foster, G. (2006). It's not your peers, and it's not your friends: Some progress toward understanding the educational peer effect mechanism. Journal of Public Economics, 90(8-9), 1455-1475.

Glewwe, P., \& Kremer, M. (2006). Schools, teachers, and education outcomes in developing countries. In E. Hanushek \& F. Welch (Eds.), (Vol. 2, p. 945-1017). Elsevier.

Hoxby, C. (2000). Peer effects in the classroom: Learning from gender and race variation (NBER Working Papers No. 7867). National Bureau of Economic Research, Inc.

Johnson, D., Johnson, R., \& Holubec, E. (1988). Cooperation in the classroom. Interaction Book Company.

Kadel, S., Kadel-Taras, S., Keehner, J., Postsecondary Teaching, L. National Center on, \& (U.S.), A. (1994). Collaborative learning: a sourcebook for higher education. National Center on Postsecondary Teaching, Learning and Assessment.

Knoef, M., \& Kooreman, P. (2011). The effects of cooperation: A structural model of siblings' caregiving interactions (IZA Discussion Papers No. 5733). Institute for the Study of Labor (IZA).

Lazear, E. P. (1985). Relative performance, sabotage and industrial politics (Tech. Rep.). University of Chicago.

Lazear, E. P., \& Rosen, S. (1981). Rank-order tournaments as optimum labor contracts. Journal of Political Economy, 89(5), 841-64. 
Lefgren, L. (2004). Educational peer effects and the chicago public schools. Journal of Urban Economics, 56(2), 169-191.

Lucas, R. J. (1988). On the mechanics of economic development. Journal of Monetary Economics, 22(1), 3-42.

Markman, J. M., Hanushek, E. A., Kain, J. F., \& Rivkin, S. G. (2003). Does peer ability affect student achievement? Journal of Applied Econometrics, 18(5), 527-544.

Mejía, D., \& St-Pierre, M. (2007). Human capital formation, inequality, and competition for jobs (DOCUMENTOS CEDE No. 004105). UNIVERSIDAD DE LOS ANDES-CEDE.

Rosenbaum, D. T. (2000). Ability, educational ranks, and labor market trends: The effects of shifts in the skill composition of educational groups (JCPR Working Papers No. 146). Northwestern University/University of Chicago Joint Center for Poverty Research.

Sacerdote, B. (2001). Peer effects with random assignment: Results for dartmouth roommates. The Quarterly Journal of Economics, 116(2), 681-704.

Schwieren, C., \& Weichselbaumer, D. (2008). Does competition enhance performance or cheating? a laboratory experiment (IZA Discussion Papers No. 3275). Institute for the Study of Labor (IZA).

Shleifer, A. (2004). Does competition destroy ethical behavior? (NBER Working Papers No. 10269). National Bureau of Economic Research, Inc.

Souza Briggs, X. de. (1997). Moving up versus moving out: Neighborhood effects in housing mobility programs. Housing Policy Debate, 8(1), 195 - 234.

Yamarik, S. (2007). Does cooperative learning improve student learning outcomes? Journal of Economic Education, 38(3), 259-277.

Zimmerman, D. J. (2003). Peer effects in academic outcomes: Evidence from a natural experiment. The Review of Economics and Statistics, 85(1), 9-23. 
Table 1: Summary Statistics for Test Scores, Competition Variables, and Individual Covariates.

\begin{tabular}{|c|c|c|c|c|c|}
\hline Variable & Obs & Mean & Std. Dev. & Min & $\operatorname{Max}$ \\
\hline \multicolumn{6}{|l|}{ Test scores } \\
\hline Mathematics test score & 78,586 & 483.715 & 107.377 & 151.67 & 815.9 \\
\hline Reading test score & 78,616 & 482.570 & 105.930 & 22.24 & 890.18 \\
\hline Science test score & 31,570 & 485.440 & 98.885 & 168.6 & 801.85 \\
\hline \multicolumn{6}{|l|}{ Competition variables } \\
\hline better $_{1}(\%)$ & 78,031 & 0.623 & 0.485 & 0 & 1 \\
\hline help $_{1}(\%)$ & 77,389 & 0.759 & 0.427 & 0 & 1 \\
\hline better $_{2}(\%)$ & 78,031 & 0.238 & 0.426 & 0 & 1 \\
\hline help $2(\%)$ & 77,389 & 0.282 & 0.450 & 0 & 1 \\
\hline Competition $_{1}$ (Author calculation) & 78,499 & 0.445 & 0.115 & 0 & 1 \\
\hline Competition $_{2}$ (Author calculation) & 75,176 & 0.448 & 0.254 & 0 & 1 \\
\hline \multicolumn{6}{|l|}{ Individual covariates } \\
\hline Younger siblings (\%) & 78,157 & 0.639 & 0.480 & 0 & 1 \\
\hline Older siblings (\%) & 78,157 & 0.642 & 0.479 & 0 & 1 \\
\hline Same age siblings (\%) & 78,835 & 0.029 & 0.168 & 0 & 1 \\
\hline Age (months) & 78,619 & 187.974 & 4.076 & 171 & 195 \\
\hline Familiy structure single (\%) & 78,206 & 0.144 & 0.351 & 0 & 1 \\
\hline Familiy structure nuclear (\%) & 78,206 & 0.753 & 0.431 & 0 & 1 \\
\hline Familiy structure mixed (\%) & 78,206 & 0.065 & 0.246 & 0 & 1 \\
\hline Familiy structure other (\%) & 78,206 & 0.038 & 0.191 & 0 & 1 \\
\hline Number of siblings & 78,157 & 1.850 & 1.388 & 0 & 12 \\
\hline Native (\%) & 75,542 & 0.934 & 0.248 & 0 & 1 \\
\hline Mom native (\%) & 75,360 & 0.879 & 0.327 & 0 & 1 \\
\hline Dad present (\%) & 78,835 & 0.889 & 0.314 & 0 & 1 \\
\hline Native language at home (\%) & 78,835 & 0.821 & 0.384 & 0 & 1 \\
\hline First child (\%) & 78,157 & 0.361 & 0.480 & 0 & 1 \\
\hline Second child (\%) & 78,157 & 0.220 & 0.415 & 0 & 1 \\
\hline Third or more child (\%) & 78,157 & 0.333 & 0.471 & 0 & 1 \\
\hline Socio economic index & 75,423 & 43.043 & 16.653 & 16 & 90 \\
\hline Highest socio economic index between mom and dad & 75,423 & 47.907 & 16.695 & 16 & 90 \\
\hline Mom level of education & 75,364 & 4.248 & 1.440 & 1 & 6 \\
\hline Instrumental motivation index & 78,692 & 0.077 & 0.984 & -2.44 & 1.48 \\
\hline Interest in reading index & 78,670 & 0.092 & 0.975 & -1.8 & 1.76 \\
\hline Interest in math index & 78,835 & 0.234 & 3.474 & -1.93 & 97 \\
\hline Control strategies index & 78,748 & 0.058 & 0.985 & -3.56 & 2.61 \\
\hline Memorizing index & 78,681 & 0.078 & 0.976 & -2.82 & 2.61 \\
\hline Elaboration strategies index & 78,684 & 0.099 & 0.999 & -2.8 & 2.49 \\
\hline Self concept (verbal) index & 78,664 & 0.028 & 0.994 & -2.62 & 1.81 \\
\hline Maths self concept index & 78,132 & 0.024 & 0.989 & -1.62 & 1.74 \\
\hline Academic self concept index & 78,788 & 0.017 & 0.996 & -2.51 & 1.85 \\
\hline Self efficacy index & 78,748 & 0.025 & 0.989 & -2.9 & 2.28 \\
\hline Control expectations index & 78,728 & 0.054 & 0.988 & -3.38 & 2.24 \\
\hline
\end{tabular}

Source: PISA (2000). Unit of observations are students who presented PISA tests, respond crosscurricular competencies questionnaire and are in schools selected for the school questionnaire. Index corresponds to warm-estimates calculated by OECD researchers. For additional information consult PISA (2000) Technical Report. 
Table 2: Summary Statistics for Household, Academic Environment and School Covariates

\begin{tabular}{|c|c|c|c|c|c|}
\hline$\overline{\text { Variable }}$ & Observations & Mean & Std. Dev. & Min & Max \\
\hline \multicolumn{6}{|l|}{ Household characteristics } \\
\hline Parental academic interest index & 77,763 & 0.044 & 1.027 & -2.2 & 2.72 \\
\hline Cultural possession index & 78,195 & 0.029 & 0.985 & -1.65 & 1.16 \\
\hline Wealth index index & 78,692 & -0.401 & 1.183 & -5.05 & 3.38 \\
\hline Home educational resources index & 78,634 & -0.260 & 1.164 & -5.93 & 0.76 \\
\hline \multicolumn{6}{|l|}{ Academic Environment } \\
\hline Time spent on homework index & 77,946 & 0.089 & 1.016 & -2.35 & 2.18 \\
\hline Teacher support index & 78,255 & 0.033 & 0.961 & -3.03 & 1.95 \\
\hline Achievement press index & 78,298 & 0.062 & 1.015 & -4.35 & 2.75 \\
\hline School disciplinary climate index & 78,324 & -0.058 & 0.989 & -2.92 & 2.96 \\
\hline Teacher-student relationship index & 78,259 & 0.099 & 1.026 & -2.9 & 2.84 \\
\hline Sense of belonging index & 78,253 & -0.009 & 0.979 & -3.4 & 2.33 \\
\hline \multicolumn{6}{|l|}{ School Characteristics } \\
\hline Total number of schooling & 71,069 & 929.076 & 192.401 & 120 & 1,680 \\
\hline Number of students in the school & 74,207 & 800.942 & 623.384 & 2 & 9815 \\
\hline Percentage of girls in the school $(\%)$ & 74,316 & 0.514 & 0.203 & 0 & 1 \\
\hline Public school (\%) & 74,485 & 0.855 & 0.352 & 0 & 1 \\
\hline School autonomy index & 74,788 & -0.053 & 0.976 & -3.22 & 1.72 \\
\hline Teacher participation to decision making index & 74,788 & -0.028 & 0.982 & -1.57 & 4.45 \\
\hline Teacher behaviors index & 76,706 & -0.025 & 1.025 & -2.41 & 3.64 \\
\hline Teacher morale index & 76,765 & -0.089 & 0.976 & -3.4 & 1.78 \\
\hline Instructional resources index & 76,769 & 0.166 & 1.093 & -1.9 & 3.22 \\
\hline Material resources index & 76,624 & -0.026 & 0.990 & -1.12 & 3.38 \\
\hline Shortage of teachers index & 76,428 & 0.030 & 1.022 & -0.95 & 3.47 \\
\hline
\end{tabular}

Source: PISA (2000). Unit of observations are students who presented PISA tests, respond crosscurricular competencies questionnaire and are in schools selected for the school questionnaire. Index corresponds to warm-estimates calculated by OECD researchers. For additional information consult PISA (2000) Technical Report. 
Table 3: OLS Estimations of Competition on Academic Performance

\begin{tabular}{|c|c|c|c|c|c|c|}
\hline & $(1)$ & $(2)$ & $(3)$ & $(4)$ & $(5)$ & $(6)$ \\
\hline \multicolumn{7}{|c|}{ Panel A: Mathematic Test Scores } \\
\hline \multirow[t]{2}{*}{ Competition } & $0.010^{* * *}$ & $0.006^{* * *}$ & $0.009^{* * *}$ & $0.008^{* * *}$ & $0.007^{* * *}$ & $0.007^{* * *}$ \\
\hline & {$[0.002]$} & {$[0.001]$} & {$[0.001]$} & {$[0.001]$} & {$[0.001]$} & {$[0.001]$} \\
\hline \multirow[t]{2}{*}{ Competition $^{2}$} & $-0.014^{* * *}$ & $-0.010 * * *$ & $-0.011 * * *$ & $-0.010^{* * *}$ & $-0.009 * * *$ & $-0.008 * * *$ \\
\hline & {$[0.001]$} & {$[0.001]$} & {$[0.001]$} & {$[0.001]$} & {$[0.001]$} & {$[0.001]$} \\
\hline Observations & 73,235 & 68,956 & 68,956 & 68,073 & 67,144 & 54,870 \\
\hline Optimal value $(\widehat{\gamma})$ & 0.372 & 0.318 & 0.386 & 0.394 & 0.383 & 0.401 \\
\hline Standard error & 0.010 & 0.010 & 0.010 & 0.010 & 0.010 & 0.020 \\
\hline p-value $\gamma=0$ & 0.000 & 0.000 & 0.000 & 0.000 & 0.000 & 0.000 \\
\hline $\mathrm{p}$-value $\gamma=1$ & 0.000 & 0.000 & 0.000 & 0.000 & 0.000 & 0.000 \\
\hline \multicolumn{7}{|c|}{ Panel B: Reading Test Scores } \\
\hline \multirow[t]{2}{*}{ Competition } & $0.007 * * *$ & $0.004^{* *}$ & $0.008^{* * *}$ & $0.008^{* * *}$ & $0.006^{* * *}$ & $0.007 * * *$ \\
\hline & {$[0.002]$} & {$[0.001]$} & {$[0.001]$} & {$[0.001]$} & {$[0.001]$} & {$[0.001]$} \\
\hline \multirow[t]{2}{*}{ Competition $^{2}$} & $-0.014^{* * *}$ & $-0.010^{* * *}$ & $-0.013^{* * *}$ & $-0.012^{* * *}$ & $-0.010^{* * *}$ & $-0.009 * * *$ \\
\hline & {$[0.001]$} & {$[0.001]$} & {$[0.001]$} & {$[0.001]$} & {$[0.001]$} & {$[0.001]$} \\
\hline Observations & 73,272 & 69,014 & 69,014 & 68,154 & 67,232 & 54,994 \\
\hline Optimal value $(\widehat{\gamma})$ & 0.242 & 0.168 & 0.321 & 0.327 & 0.307 & 0.364 \\
\hline Standard error & 0.010 & 0.010 & 0.010 & 0.010 & 0.010 & 0.020 \\
\hline p-value $\gamma=0$ & 0.000 & 0.000 & 0.000 & 0.000 & 0.000 & 0.000 \\
\hline p-value $\gamma=1$ & 0.000 & 0.000 & 0.000 & 0.000 & 0.000 & 0.000 \\
\hline Child characteristics & & Yes & Yes & Yes & Yes & Yes \\
\hline Region fixed effects & & & Yes & Yes & Yes & Yes \\
\hline Household characteristics & & & & Yes & Yes & Yes \\
\hline Academic environment & & & & & Yes & Yes \\
\hline School characteristics & & & & & & Yes \\
\hline
\end{tabular}

Note: PISA (2000). Beta standardized coefficients presented for an increase of competition in one percentage point. Unit of observations are students who presented PISA tests, respond cross-curricular competencies questionnaire and are in schools selected for the school questionnaire. Clustered standard errors at group level presented in brackets. Standard error for optimal values estimated with delta method. ${ }^{* * *} \mathrm{p}<0.01,{ }^{* *} \mathrm{p}<0.05,{ }^{*} \mathrm{p}<0.1$. 
Table 4: First Stage for Competition Levels

\begin{tabular}{|c|c|c|c|c|c|c|}
\hline & (1) & (2) & (3) & (4) & (5) & (6) \\
\hline \multicolumn{7}{|c|}{ Panel A: Competition } \\
\hline \multirow[t]{2}{*}{ No siblings } & $0.027 * * *$ & $0.019^{* * *}$ & $0.027^{* * *}$ & $0.026^{* * *}$ & $0.027 * * *$ & $0.025 * * *$ \\
\hline & {$[0.005]$} & {$[0.005]$} & {$[0.005]$} & {$[0.005]$} & {$[0.005]$} & {$[0.005]$} \\
\hline \multirow[t]{2}{*}{ Older Siblings } & $-0.013^{* * *}$ & $-0.016^{* * *}$ & 0.001 & 0.001 & 0.000 & $-0.006^{* *}$ \\
\hline & {$[0.003]$} & {$[0.003]$} & {$[0.003]$} & {$[0.003]$} & {$[0.003]$} & {$[0.003]$} \\
\hline Observations & 74,801 & 70,417 & 70,417 & 69,499 & 68,537 & 56,001 \\
\hline F-statistic & 51.06 & 37.52 & 17.55 & 17.06 & 18.07 & 21.02 \\
\hline \multicolumn{7}{|c|}{ Panel B: Competition ${ }^{2}$} \\
\hline \multirow[t]{2}{*}{ No siblings } & $0.029^{* * *}$ & $0.026^{* * *}$ & $0.024^{* * *}$ & $0.024^{* * *}$ & $0.023^{* * *}$ & $0.022^{* * *}$ \\
\hline & {$[0.004]$} & {$[0.005]$} & {$[0.004]$} & {$[0.004]$} & {$[0.004]$} & {$[0.005]$} \\
\hline \multirow[t]{2}{*}{ Older Siblings } & -0.004 & $-0.008 * * *$ & $0.006^{* *}$ & $0.006^{* *}$ & $0.005^{*}$ & 0.001 \\
\hline & {$[0.002]$} & {$[0.003]$} & {$[0.003]$} & {$[0.003]$} & {$[0.003]$} & {$[0.003]$} \\
\hline Observations & 74,801 & 70,417 & 70,417 & 69,499 & 68,537 & 56,001 \\
\hline F-statistic & 39.00 & 33.62 & 14.09 & 13.91 & 13.08 & 11.61 \\
\hline Child characteristics & & Yes & Yes & Yes & Yes & Yes \\
\hline Region fixed effects & & & Yes & Yes & Yes & Yes \\
\hline Household characteristics & & & & Yes & Yes & Yes \\
\hline Academic environment & & & & & Yes & Yes \\
\hline School characteristics & & & & & & Yes \\
\hline
\end{tabular}

Note: PISA (2000). Unit of observations are students who presented PISA tests, respond cross-curricular competencies questionnaire and are in schools selected for the school questionnaire. Robust standard errors presented in brackets. ${ }^{* * *} \mathrm{p}<0.01,{ }^{* *} \mathrm{p}<0.05,{ }^{*} \mathrm{p}<0.1$. 
Table 5: IV Estimations of Competition on Academic Performance

\begin{tabular}{|c|c|c|c|c|c|c|}
\hline & (1) & $(2)$ & $(3)$ & $(4)$ & $(5)$ & $(6)$ \\
\hline \multicolumn{7}{|c|}{ Panel A: Mathematic Test Scores } \\
\hline \multirow[t]{2}{*}{ Competition } & $0.737^{* * *}$ & $0.468^{* * *}$ & $1.004^{* * *}$ & $0.912^{* * *}$ & $0.866^{* * *}$ & $0.709^{* *}$ \\
\hline & {$[0.206]$} & {$[0.180]$} & {$[0.365]$} & {$[0.342]$} & {$[0.328]$} & {$[0.278]$} \\
\hline \multirow[t]{2}{*}{ Competition $^{2}$} & $-0.627^{* * *}$ & $-0.328^{*}$ & $-1.031^{* *}$ & $-0.929 * *$ & $-0.911^{* *}$ & $-0.772^{* *}$ \\
\hline & {$[0.240]$} & {$[0.192]$} & {$[0.406]$} & {$[0.378]$} & {$[0.388]$} & {$[0.383]$} \\
\hline Observations & 73,229 & 68,956 & 68,956 & 68,073 & 67,144 & 54,870 \\
\hline Optimal value $(\widehat{\gamma})$ & 0.588 & 0.714 & 0.487 & 0.491 & 0.475 & 0.459 \\
\hline Standard error & 0.15 & 0.47 & 0.13 & 0.14 & 0.14 & 0.16 \\
\hline p-value $\gamma=0$ & 0.000 & 0.128 & 0.000 & 0.001 & 0.001 & 0.004 \\
\hline $\mathrm{p}$-value $\gamma=1$ & 0.005 & 0.541 & 0.000 & 0.000 & 0.000 & 0.001 \\
\hline Hansen Test & 3.882 & 2.883 & 0.000 & 0.010 & 0.000 & 0.051 \\
\hline p-value & 0.049 & 0.09 & 0.988 & 0.922 & 0.997 & 0.822 \\
\hline Endogeneity test & 181.4 & 92.48 & 260 & 219.3 & 206.6 & 162.5 \\
\hline $\mathrm{p}$-value & 0.000 & 0.000 & 0.000 & 0.000 & 0.000 & 0.000 \\
\hline \multicolumn{7}{|c|}{ Panel B: Reading Test Scores } \\
\hline \multirow[t]{2}{*}{ Competition } & $0.675^{* * *}$ & $0.380^{* *}$ & $1.172^{* * *}$ & $1.056^{* * *}$ & $0.982^{* * *}$ & $0.746^{* * *}$ \\
\hline & {$[0.202]$} & {$[0.160]$} & {$[0.437]$} & {$[0.404]$} & {$[0.372]$} & {$[0.275]$} \\
\hline \multirow[t]{2}{*}{ Competition $^{2}$} & $-0.549^{* *}$ & -0.252 & $-1.162^{* *}$ & $-1.033^{* *}$ & $-0.994^{* *}$ & $-0.768^{* *}$ \\
\hline & {$[0.228]$} & {$[0.167]$} & {$[0.478]$} & {$[0.436]$} & {$[0.426]$} & {$[0.363]$} \\
\hline Observations & 73,267 & 69,014 & 69,014 & 68,154 & 67,232 & 54,994 \\
\hline Optimal value $(\widehat{\gamma})$ & 0.615 & 0.754 & 0.505 & 0.511 & 0.494 & 0.486 \\
\hline Standard error & 0.19 & 0.65 & 0.15 & 0.16 & 0.15 & 0.16 \\
\hline p-value $\gamma=0$ & 0.001 & 0.247 & 0.001 & 0.002 & 0.001 & 0.003 \\
\hline p-value $\gamma=1$ & 0.04 & 0.705 & 0.001 & 0.003 & 0.001 & 0.001 \\
\hline Hansen Test & 4.232 & 3.813 & 0.01 & 0.04 & 0.004 & 0.002 \\
\hline $\mathrm{p}$-value & 0.040 & 0.051 & 0.919 & 0.841 & 0.950 & 0.964 \\
\hline Endogeneity test & 166.5 & 73.1 & 300.7 & 261 & 245.3 & 189.4 \\
\hline $\mathrm{p}$-value & 0.000 & 0.000 & 0.000 & 0.000 & 0.000 & 0.000 \\
\hline Child characteristics & & Yes & Yes & Yes & Yes & Yes \\
\hline Region fixed effects & & & Yes & Yes & Yes & Yes \\
\hline Household characteristics & & & & Yes & Yes & Yes \\
\hline Academic environment & & & & & Yes & Yes \\
\hline School characteristics & & & & & & Yes \\
\hline
\end{tabular}

Note: PISA (2000). Beta standardized coefficients presented for an increase of competition in one percentage point. Unit of observations are students who presented PISA tests, respond cross-curricular competencies questionnaire and are in schools selected for the school questionnaire. Clustered standard errors at group level presented in brackets. Standard error for optimal values estimated with delta method. ${ }^{* *} \mathrm{p}<0.01,{ }^{* *} \mathrm{p}<0.05,{ }^{*} \mathrm{p}<0.1$. 
Table 6: Optimal Competition Values for OLS

\begin{tabular}{|c|c|c|c|c|c|c|}
\hline \multicolumn{7}{|c|}{ Panel A: Mathematics below the median value } \\
\hline Optimal value $(\widehat{\gamma})$ & 0.405 & 0.406 & 0.374 & 0.387 & 0.294 & 0.326 \\
\hline Standard error & 0.010 & 0.020 & 0.030 & 0.030 & 0.090 & 0.130 \\
\hline p-value $\gamma=0$ & 0.000 & 0.000 & 0.000 & 0.000 & 0.001 & 0.015 \\
\hline p-value $\gamma=1$ & 0.000 & 0.000 & 0.000 & 0.000 & 0.000 & 0.000 \\
\hline Observations & 35,925 & 33,350 & 33,350 & 32,651 & 32,031 & 26,664 \\
\hline \multicolumn{7}{|c|}{ Panel B: Mathematics above the median value } \\
\hline Optimal value $(\widehat{\gamma})$ & 0.338 & 0.483 & 0.400 & 0.425 & 0.432 & 0.432 \\
\hline Standard error & 0.060 & 0.010 & 0.380 & 0.680 & 2.520 & 3.000 \\
\hline p-value $\gamma=0$ & 0.000 & 0.000 & 0.296 & 0.534 & 0.864 & 0.886 \\
\hline p-value $\gamma=1$ & 0.000 & 0.000 & 0.117 & 0.401 & 0.822 & 0.850 \\
\hline Observations & 36,320 & 34,780 & 34,780 & 34,611 & 34,314 & 27,656 \\
\hline \multicolumn{7}{|c|}{ Panel C: Reading below the median value } \\
\hline Optimal value $(\widehat{\gamma})$ & 0.302 & 0.273 & 0.291 & 0.300 & 0.177 & 0.214 \\
\hline Standard error & 0.010 & 0.020 & 0.010 & 0.020 & 0.030 & 0.060 \\
\hline p-value $\gamma=0$ & 0.000 & 0.000 & 0.000 & 0.000 & 0.000 & 0.000 \\
\hline p-value $\gamma=1$ & 0.000 & 0.000 & 0.000 & 0.000 & 0.000 & 0.000 \\
\hline Observations & 35,508 & 32,846 & 32,846 & 32,151 & 31,474 & 26,284 \\
\hline \multicolumn{7}{|c|}{ Panel D: Reading above the median value } \\
\hline Optimal value $(\widehat{\gamma})$ & 0.029 & -0.541 & 0.337 & 0.331 & 0.309 & 0.351 \\
\hline Standard error & 0.060 & 0.040 & 0.060 & 0.080 & 0.140 & 0.160 \\
\hline p-value $\gamma=0$ & 0.624 & 2.000 & 0.000 & 0.000 & 0.026 & 0.033 \\
\hline p-value $\gamma=1$ & 0.000 & 0.000 & 0.000 & 0.000 & 0.000 & 0.000 \\
\hline Observations & 36,755 & 35,327 & 35,327 & 35,179 & 34,945 & 28,149 \\
\hline Child characteristics & & Yes & Yes & Yes & Yes & Yes \\
\hline Region fixed effects & & & Yes & Yes & Yes & Yes \\
\hline Household characteristics & & & & Yes & Yes & Yes \\
\hline Academic environment & & & & & Yes & Yes \\
\hline School characteristics & & & & & & Yes \\
\hline
\end{tabular}

Note: PISA (2000). Unit of observations are students who presented PISA tests, respond cross-curricular competencies questionnaire and are in schools selected for the school questionnaire. Clustered standard errors at group level. Standard error for optimal values estimated with delta method. 
Table 7: Optimal Competition Values for IV

\begin{tabular}{|c|c|c|c|c|c|c|}
\hline \multicolumn{7}{|c|}{ Panel A: Mathematics below the median value } \\
\hline Optimal value $(\widehat{\gamma})$ & 1.38 & 15.91 & 0.50 & 0.52 & 0.46 & 0.41 \\
\hline Standard error & 20.53 & 501,488 & 0.14 & 0.15 & 0.17 & 0.33 \\
\hline p-value $\gamma=0$ & 0.95 & 1.00 & 0.00 & 0.00 & 0.01 & 0.21 \\
\hline p-value $\gamma=1$ & 1.02 & 1.00 & 0.00 & 0.00 & 0.00 & 0.07 \\
\hline Observations & 35,921 & 33,350 & 33,350 & 32,651 & 32,031 & 26,664 \\
\hline \multicolumn{7}{|c|}{ Panel B: Mathematics above the median value } \\
\hline Optimal value $(\widehat{\gamma})$ & 0.60 & 0.64 & 0.51 & 0.52 & 0.52 & 0.52 \\
\hline Standard error & 1.96 & 1.80 & 0.80 & 0.82 & 0.51 & 0.47 \\
\hline p-value $\gamma=0$ & 0.76 & 0.72 & 0.52 & 0.53 & 0.31 & 0.27 \\
\hline p-value $\gamma=1$ & 0.84 & 0.84 & 0.54 & 0.55 & 0.35 & 0.31 \\
\hline Observations & 36,319 & 34,780 & 34,780 & 34,611 & 34,314 & 27,656 \\
\hline \multicolumn{7}{|c|}{ Panel C: Reading below the median value } \\
\hline Optimal value $(\widehat{\gamma})$ & 0.89 & 1.88 & 0.45 & 0.47 & 0.43 & 0.39 \\
\hline Standard error & 2.92 & 78.75 & 0.48 & 0.50 & 0.70 & 0.88 \\
\hline p-value $\gamma=0$ & 0.76 & 0.98 & 0.36 & 0.35 & 0.54 & 0.66 \\
\hline p-value $\gamma=1$ & 0.97 & 1.01 & 0.25 & 0.29 & 0.41 & 0.49 \\
\hline Observations & 35,504 & 32,846 & 32,846 & 32,151 & 31,474 & 26,284 \\
\hline \multicolumn{7}{|c|}{ Panel D: Reading above the median value } \\
\hline Optimal value $(\widehat{\gamma})$ & 0.62 & 0.63 & 0.56 & 0.55 & 0.54 & 0.56 \\
\hline Standard error & 0.55 & 0.41 & 0.25 & 0.22 & 0.18 & 0.21 \\
\hline p-value $\gamma=0$ & 0.26 & 0.12 & 0.02 & 0.01 & 0.00 & 0.01 \\
\hline p-value $\gamma=1$ & 0.48 & 0.36 & 0.07 & 0.04 & 0.01 & 0.03 \\
\hline Observations & 36,755 & 35,327 & 35,327 & 35,179 & 34,945 & 28,149 \\
\hline Child characteristics & & Yes & Yes & Yes & Yes & Yes \\
\hline Region fixed effects & & & Yes & Yes & Yes & Yes \\
\hline Household characteristics & & & & Yes & Yes & Yes \\
\hline Academic environment & & & & & Yes & Yes \\
\hline School characteristics & & & & & & Yes \\
\hline
\end{tabular}

Note: PISA (2000). Unit of observations are students who presented PISA tests, respond cross-curricular competencies questionnaire and are in schools selected for the school questionnaire. Clustered standard errors at group level. Standard error for optimal values estimated with delta method. 
Figure 1: Distribution of Test Scores

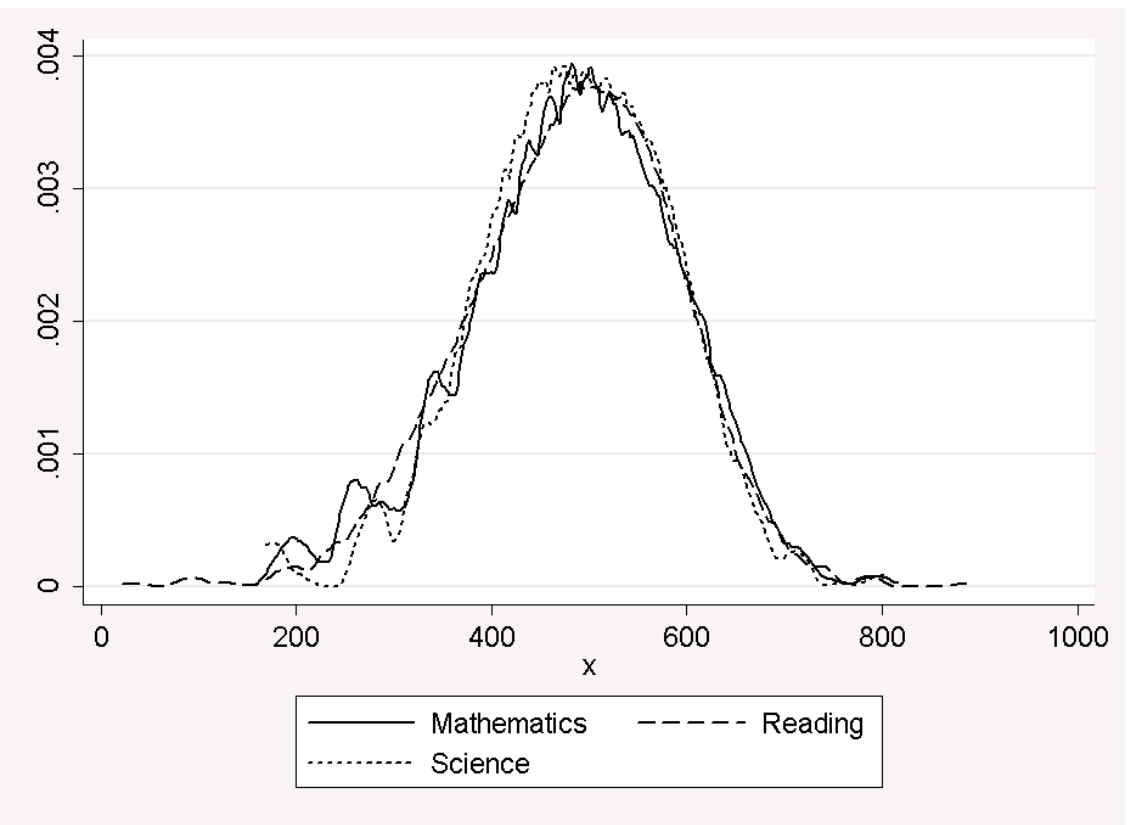

Note: Test scores distribution for each cognitive are using the whole sample.

Figure 2: Relationship Between Test Scores and Competition Levels

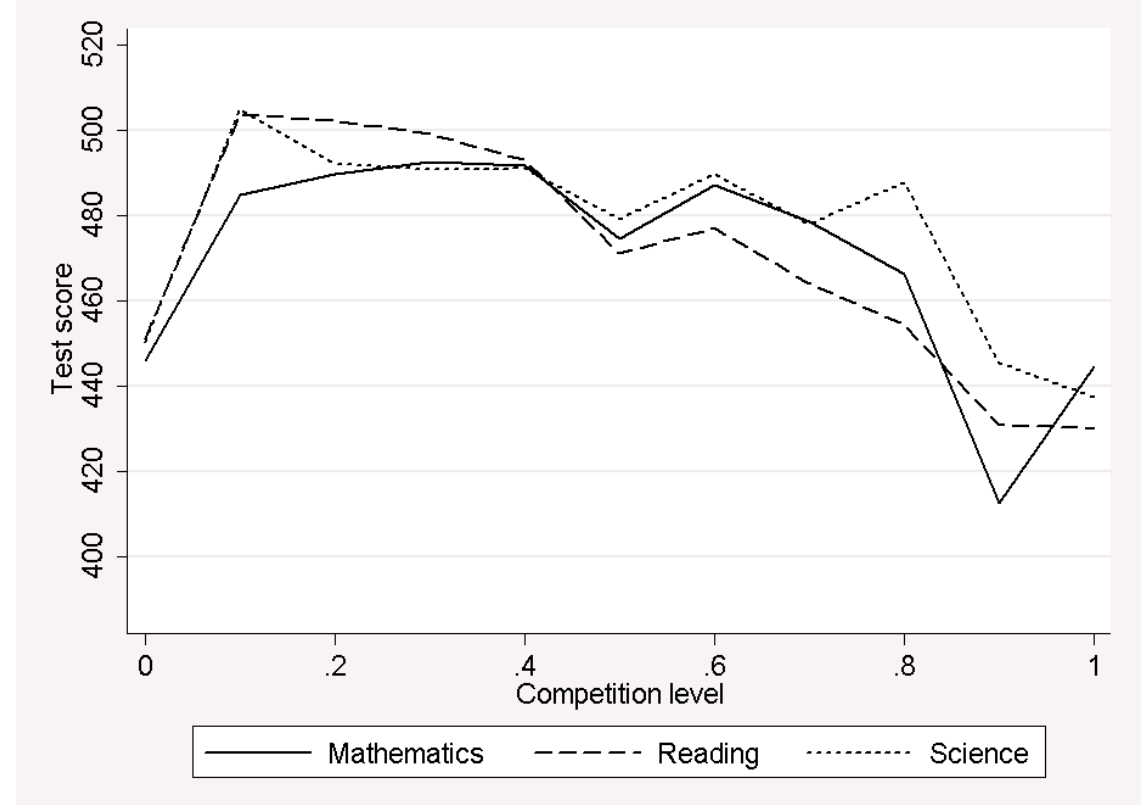

Note: Competition measure is number 1 without using instrumental variables. For each competition value the mean of each test score is graphed. 
Figure 3: No-parametric Estimation of Competition on Mathematics Test Scores

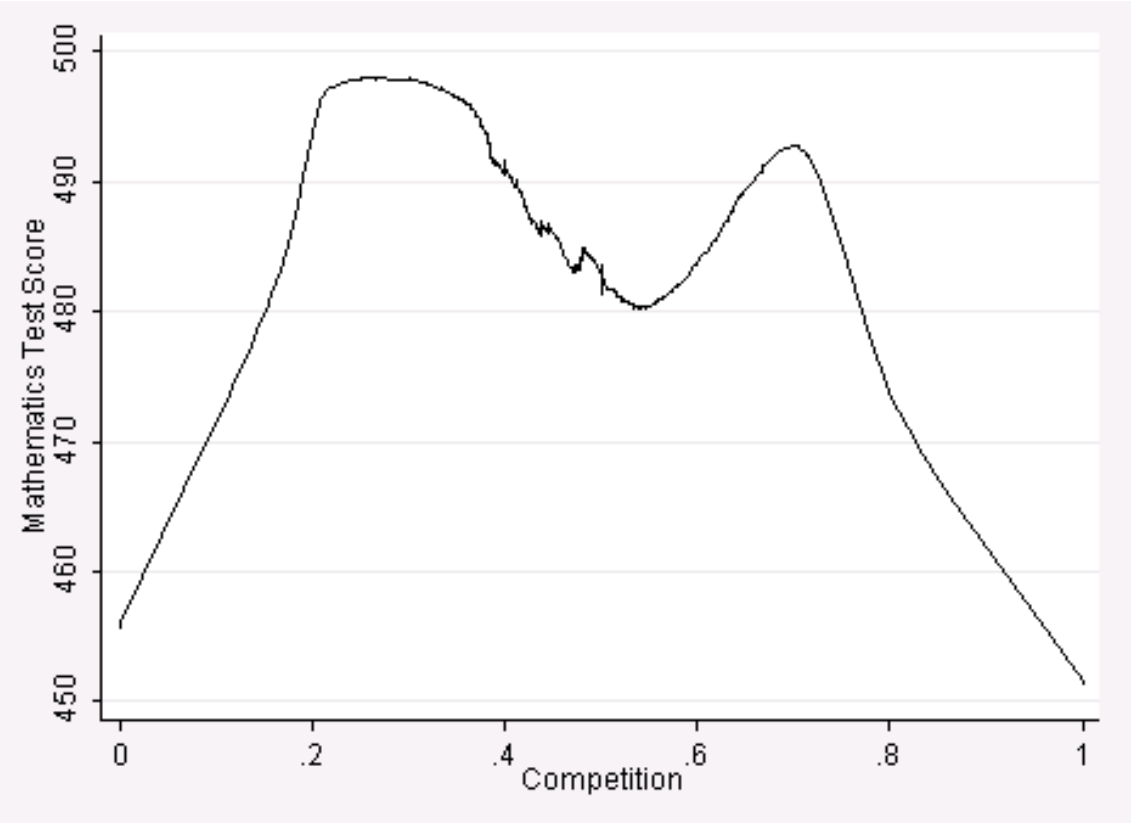

Note: Test scores distribution for each cognitive are using the whole sample.

Figure 4: No-parametric Estimation of Competition Predicted Values on Mathematics Test Scores

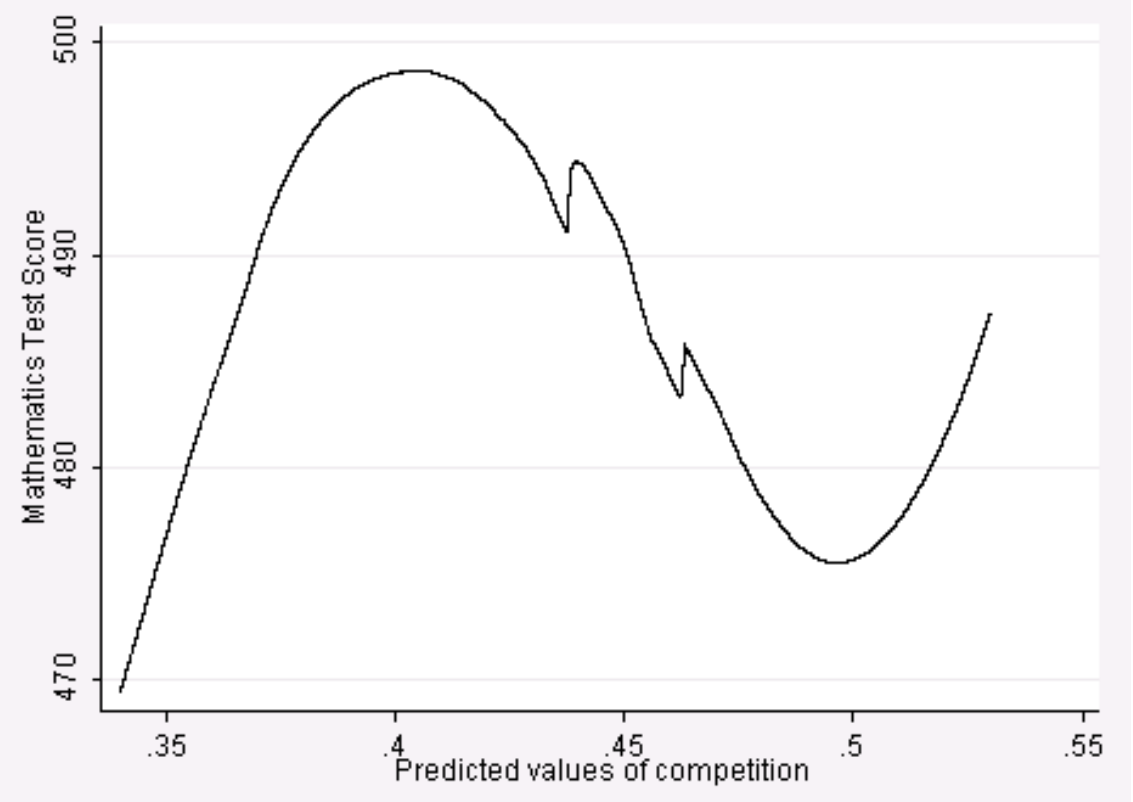

Note: Competition measure is predicted from column 6 of table 4 using instrumental variables. The graph is shown for the $90 \%$ of the whole sample, eliminating data below the percentile $5^{t h}$ or above the percentile $95^{t h}$ of the predicted values of competition. 
$\prod_{1}^{\text {Universidad de }}$

\section{SISTEMA DE BIBLIOTECAS IDENTIFICACIÓN TRABAJO DE GRADO}

FECHADE ELABORACIÓN

DD MM AAAA

$23 \quad 01 \quad 2012$

NIT: $860.007 .386-1$

1. IDENTIFICACIÓN AUTOR(ES) DEL TRABAJO DE GRADO

DOCUMENTO DE IDENTIDAD

CÓDIGO

TIPO NÚMERO

200621518

CC 1020733795
$\mathrm{CC}$

$\mathrm{CC}$

CC

$\mathrm{CC}$

CC

PROGRAMA Maestria

FACULTAD Facultad de Economia

DEPARTAMENTO No Aplica
ENTREGÓ FORMATO:

SB-10 "Entrega trabajo de grado y autorización de uso a favor de la Universidad de los Andes",

Documento con el cual, el autor permite que su trabajo sea

SB-10: utilizado por la Universidad, para fines de consulta y de mención en sus catàiogos bibliográficos, tanto fisicos como en linea.

1.1 IDENTIFICACION DE TRABAJO DE GRADO PARA DOB LE TITULACIÓN

\begin{tabular}{llc}
\hline PROGRAMA & No Aplica & TESIS PARA DOBLE TITULACION: \\
FACULTAD & No Aplica & Si el trabajo de grado presentado aplica para obtener dos (2) \\
titulaciones, por favor marque esta casilla y diligencie la & información de esta sección.
\end{tabular}

DEPARTAMENTO No Aplica

2. INFORMACIÓN GENERAL DEL TRABAJO DE GRADO

TITULO DEL TRABAIO DE GRADO:

Peer Effects, Cooperation and Competition in Human Capital Formation.

DESCRIPCIÓN FISICA

Número de

páginas:

llustraciones
MATERIAL ACOMPAÑANTE (Cantidad):

Casetes Audio:

Discos compactos:

Casetes Video

Disquetes:
Diapositivas:

Orros: ¿Cuáles?
FECHADE ELABORACIÓN DD MM AAAA

RESUMEN DEL TRABAJO DE GRADO

Economic literature has identified positive effects of peer abilities on individual achievement.

However, the intuitive arguments supporting this evidence are not clear. This article presents a

How cooperation and competition among group members; more precisely, the

presence of positive and negative externalities in human capital accumulation. First, I develop

presence of an

optimal level of competition between group members that maximizes human capital accumulation.

Then, using data from PISA (2000) and an empirical strategy that controls for potential

Then

endogeneity issues, I find robust evidence of a non-linear effect of competition on academic

model.

technological externalities in educational production functions.

OB.JETIVOS DEL TRABA.JO DE GRADO:

$\cdots$

METODOLOGIA DEL TRABAJO DE GRADO:

. .

CONCLUSIONES DEL TRABAJO DE GRADO 
$\cdots$

PALABRAS CLAVES (TEMAS) DEL TRABAIO DE GRADO:

peer effects, Cooperation, Competition, PISA.

ACUERDOS DE CONFIDENCIALIDAD: " NO TIENE ACUERDO(S) TIENE ACUERDO(S)

Si selecciona tener acuerdo de confidencialidad, por favor diligencie el siguiente cuadro:

Persona natural o juridica

DD Mesde $\begin{gathered}\text { Hasta } \\ \text { MM }\end{gathered}$

\section{FIRMAS}

AUTORES (Nombre completo)

Román Andrés Eerirate Vaisg-uez

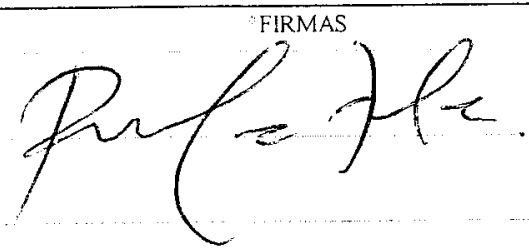

DIRECTORES / ASESORES (Nombre completo)

\section{Diniel Mejic}

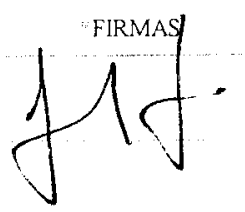

IURADO / LECTOR (Nombre completo)

\section{Daniel Meji-}
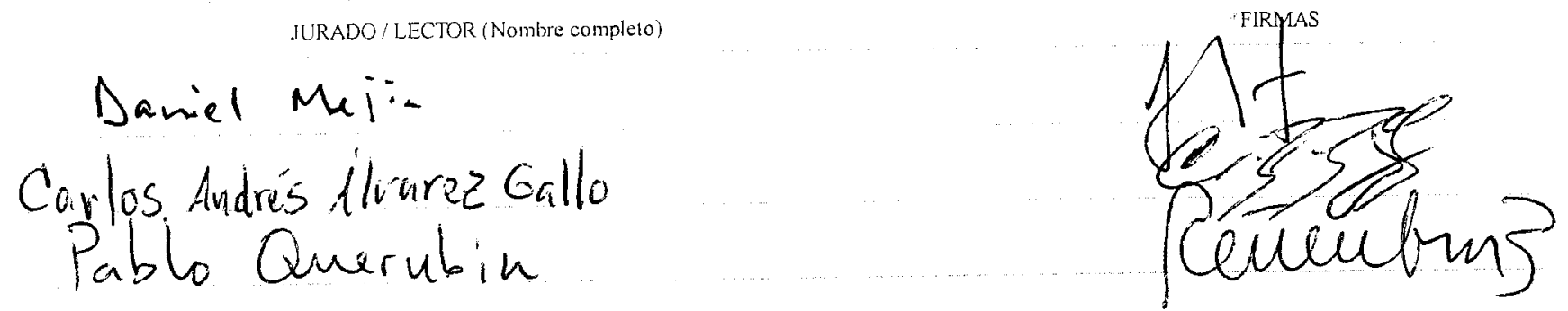

Las firmas de Autor y Director/Asesor son obligatorias. Si tiene inconveniemes con el registro de la firma del Jurado/Lector, deberá tramitar ante la respectiva Facul tad la Las firmas de Autor y Director/Asesor son obligatorias. Si tiene inconvenientes con el registro de la firm
autorizacion para registrar las firmas de pares o un sello que justifique la ausencia de la firma faltante. 
MUniversidad de

\section{ENTREGA EJEMPLAR TRABAJO DE GRADO $Y$ AUTORIZACIÓN DE SU USO A FAVOR DE LA UNIVERSIDAD DE LOS ANDES}

Yo Román Andrés Zárate

identificado con la Cédula de Ciudadanía No 1020733795 de Eogotá calidad de autor del trabajo de tesis, monografía Feer Effects, Cooperation and Competition in Human Capital Formation
- mayor de edad, vecino de Bogotá D.C., , actuando en nombre propio, en mi trabajo de grado denominado:

hago entrega del ejemplar respectivo y de sus anexos del ser el caso, en formato digital o electrónico (CD-ROM) y autorizo a LA UNIVERSIDAD DE LOS ANDES, para que en los términos establecidos en la Ley 23 de 1982 , Ley 44 de 1993 , Decisión Andina 351 de 1993, Decreto 460 de 1995 y demás normas generales sobre la materia, utilice y use en todas sus formas, los derechos patrimoniales de reproducción, comunicación pública, transformación y distribución (alquiler, préstamo público e importación) que me corresponden como creador de la obra objeto del presente documento. PARÁGRAFO: La presente autorización se hace extensiva no sólo a las facultades y derechos de uso sobre la obra en formato o soporte material, sino también para formato virtual, electrónico, digital, óptico, usos en red, internet, extranet, intranet, etc., y en general para cualquier formato conocido o por conocer.

EL AUTOR - ESTUDIANTES, manifiesta que la obra objeto de la presente autorización es original y la realizó sin violar o usurpar derechos de autor de terceros, por lo tanto la obra es de su exclusiva autoria y tiene la titularidad sobre la misma. PARÁGRAFO: En caso de presentarse cualquier reclamación o acción por parte de un tercero en cuanto a los derechos de autor sobre la obra en cuestión, EL ESTUDIANTE - AUTOR, asumirá toda la responsabilidad, y saldrá en defensa de los derechos aquí autorizados; para todos los efectos la Universidad actúa como un tercero de buena fe.

Para constancia se firma el presente documento en dos (02) ejemplares del mismo valor y tenor, en Bogotá D.C., a los veinticuatro 24 días del mes de enero

2012 .

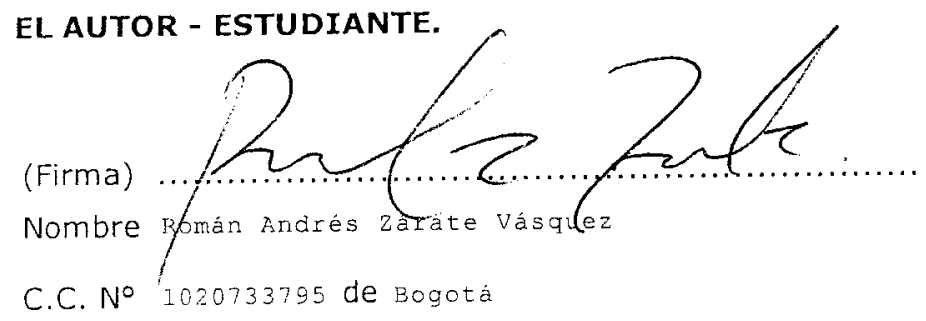

